

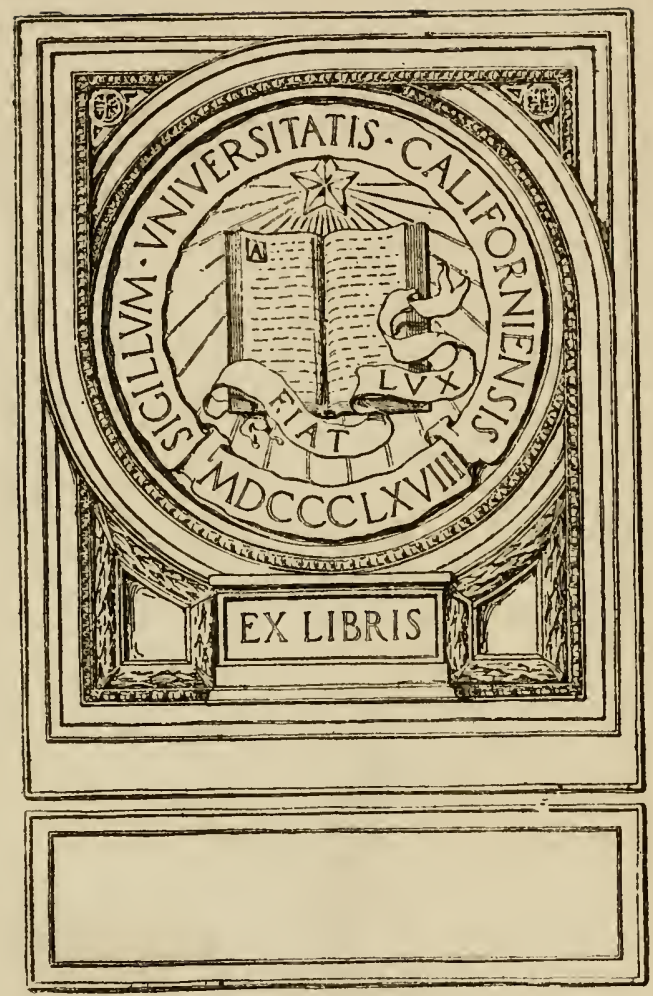




\section{.}





\title{
A Method of Measuring the Development of the Intelligence of Young Children
}

\author{
By Alfred Binet and Th. Simon
}

\section{AUTHORIZED TRANSLATION WITH PREFACE}

And an Appendix, Containing an Arrangement of the Tests in Age and Diagnostic Groups for Convenience in Conducting Examinations

$$
\text { By Clara Harrison Town, Ph. D. }
$$

Author of "Two Experimental Studies of the Insane." Formerly State Psychologist, Lincoln State School and Colony, Lincoln, Ill.

Third Edition.

CHICAGO MEDICAL BOOK CO.

Chicago

1915 
Copyright I9I5

By

Clara Harrison Town. 


\section{TRANSLATOR'S PREFACE.}

The article here translated appeared in the "Bulletin de la Société libre pour l'Etude Psychologique de l'Enfant," April, 1911. It is a brief but complete statement of the BinetSimon method of examining the intelligence and determining the mental level of children.

The aim of the authors was to present their system of tests as finally revised with adequate explanation and instruction for its use, but without the theoretical and philosophical discussion accompanying its presentation in "L'Année Psychologique." It is in fact a convenient manual for those who wish to use the method.

The translator is of the opinion that just such a manual is needed in the United States at the present time. So much has appeared in our educational press concerning the BinetSimon System and the practical value of its application to the problems of special education that a widespread interest has been awakened; indeed the system has become popular. Unfortunately, this popularity is not paralleled by accurate knowledge concerning it. The surface simplicity of the method has encouraged many to attempt its application with little more knowledge concerning it than that supplied by the list of tests. This is undoubtedly largely owing to the fact that none of the Binet-Simon articles on the subject have been translated in full; extracts have appeared and many criticisms, but the articles themselves have never appeared in English form. To put into the hands of our educational public the Binet-Simon System in the form and with the instructions and explanations presented by its authors, this translation has been prepared.

The series of tests presented in the 1911 article is the result of a gradual development. The first form of the Scale was published in "L'Année Psychologique" in 1905; this itself 
was the result of much observation and study of the developing child mind. During extended study many simple tests were tried, many were discarded, and those that finally survived did so only by virtue of their intrinsic value brought out by actual trial. The result was a hierarchy of tests arranged in the order of their increasing difficulty, one group adapted to children of one and two years, and other groups to children of four, five, six, seven, eight, nine, ten, eleven and twelve years.

In 1904 an educational measure in Paris required the selection of all the mentally defective children in the public schools, such selection to be made by means of individual examinations. There was at that time no definite method of making such examination, and with the object of supplying one, Binet and Simon determined to standardize their scale of tests. In order to do this, selected groups of pedagogically average public school children were examined-ten each of the ages three to six, and fifteen each of the ages seven to twelve, inclusive. The series of tests was finally arranged in age groups according to the results of these examinations and those previously conducted.

The Scale was thus standardized. It remained to adapt it to the diagnosis of feeble-minded conditions. This was achieved by correlating it with the classification of the feebleminded then most generally accepted-the tripartite one into idiots, imbeciles and morons. (The last term varies in different countries; moron is the accepted term in the United. States.) The idiots are those of least mentality, the imbeciles those of next higher grade, and the morons those more closely approximating the normal in type. There was, however, no distinct line of demarkation between the mental condition of the idiot and the imbecile, or between that of the imbecile and the moron. The criteria most generally used were differences in ability to dress, to eat, and to perform various kinds of work. There, however, was no certainty that a case 
would be diagnosed in the same way by different examiners; the personal equation necessarily entered into all diagnoses. Binet was of the opinion that uniformity of diagnosis should be secured, and he succeeded in devising a plan which, if generally accepted, would doubtless secure it. Being a student of language development, and holding the opinion that in intellectual development language is so intimately involved that it may be considered as one criterion of intellectual level, he used three great planes of language development to differentiate between the mental conditions of idiots, imbeciles and morons. According to this classification the idiot never reaches the plane of spoken language; he is limited to the use and understanding of gesture; the imbecile understands spoken language and talks himself in varying degrees of fluency; the moron, in addition to using spoken language, is capable of learning to read and write. Applying this differentiation to the Scale, the idiots fall to the age groups one and two, the imbeciles to the age groups three, four, five, six and seven, and the morons to the age groups eight, nine, ten, eleven and twelve. Further than the twelve year level the feeble-minded individual seems not to develop.

The feeble-minded patients at the Salpetrière were examined by the Scale and it proved to be a most satisfactory means of diagnosis, for the reason that each diagnosis carried with it a distinct idea of the child's mental status.

In 1908 the first revision of the Scale appeared, published as the result of further experimental work with the method. This is the form of the Scale most used in the United States. Between 1908 and 1911, the Scale was applied by various experimenters as well as by the originators, and as a result of the combined findings the final revision of the Scale was published in 1911. It appeared in "L'Année Psychologique" in the article entitled "Nouvelle Recherches sur la Mesure du Niveau intellectuel chez les Enfants d'Ecole," and in the "Bulletin de la Société libre pour l'Etude psychologique 
de l'Enfant," in the article here translated- "La mesure du Developpement de l'Intelligence chez jeunes Enfants."

In conclusion the translator wishes to express her sincere thanks to M. Th. Simon and to Mlle. Giroud, editor of the "Bulletin de la Société libre pour l'Etude Psychologique de l'Enfant" for their kindness in granting permission to publish this translation.

Clara Harrison Town. 


\section{A METHOD OF MEASURING THE DEVELOPMENT OF THE INTELLIGENCE OF YOUNG CHILDREN.*}

\section{ALFRED BINET AND T. SIMON.}

The method here presented is one by which the intelligence of a child may be estimated. The method consists in asking the child some precise questions and having him perform some simple experiments; these questions and experiments are called tests." As much research has revealed which of these tests a normal child passes successfully at a given age, it is easy to ascertain whether the child under examination gives results equal to the normal child of his age, or whether he is advanced or retarded in relation to this norm.

The series of tests used in the method, grouped according to age, are as follows:

\section{THREE YEARS.}

Shows nose, eyes and mouth.

Repeats two digits.

Enumerates objects in a picture.

Gives family name.

Repeats a sentence of six syllables.

\footnotetext{
*We explain here very succinctly our method for measuring the level of the intelligence of a child. We omit all theory, philosophy, and discussion, referring the reader interested in these questions to L'Annee Psychologique, 1908, p. 1, and 1911, p. 145. In the Bulletin only those details will be given which it is necessary to know in order to apply the method.

The present brochure completes that of M. Vaney (No. 68 of the Bulletin, February, 1911) on the "Classes for Backward Children." The two brochures sum up all which concerns the recruiting, organization and instruction of these classes.
} 
FOUR YEARS.

Gives own sex.

Names key, knife and penny.

Repeats three digits.

Compares two lines.

FIVE YEARS.

Compares two weights.

Copies a square.

Repeats a sentence of ten syllables.

Counts four pennies.

Game of patience with two pieces.

SIX YEARS.

Distinguishes between morning and afternoon.

Defines in terms of use.

Copies a lozenge.

Counts thirteen pennies.

Compares faces from the aesthetic point of view.

SEVEN YEARS.

Right hand; left ear.

Describes a picture.

Executes 3 commissions.

Gives value of 9 sous, three of which are double.

Names 4 colors.

\section{EIGHT YEARS.}

Compares two remembered objects.

Counts from 20 to 0.

Indicates omissions in pictures.

Gives day and date.

Repeats 5 digits. 
NINE YEARS,

Gives change from 20 sous.

Defines in terms superior to use.

Recognizes all the pieces of our money.

Enumerates the months.

Understands easy questions.

$$
\text { TEN YEARS. }
$$

Arranges five weights.

Copies drawings from memory.

Criticises absurd statements.

Understands difficult questions.

Uses 3 given words in two sentences.

TWELVE YEARS.

Resists suggestion (length of lines).

Composes one sentence containing 3 given words.

Says more than sixty words in 3 minutes.

Defines abstract terms.

Discovers the sense of a sentence the words of which are mixed.

FIFTEEN YEARS.

Repeats 7 digits.

Gives 3 rhymes.

Repeats a sentence of 26 syllables.

Interprets a picture.

Solves a problem from several facts.

ADULT.

Solves the paper cutting test.

Rearranges a triangle.

Gives differences of meanings of abstract terms.

Solves the question of the President.

Gives the resumé of the thought of Hervieu. 
We give first the description of the tests and the instructions necessary for their application. In a second part we point out the general conditions to be observed in holding examinations, and the methods of calculation used in estimating the intelligence of children. 


\section{PART I.}

\section{DESCRIPTION OF TESTS.}

\section{CHILDREN OF THREE YEARS.}

I. Shows nose, eyes and mouth.-To perform the test one should look steadily at the child, attract his attention, and repeat several times: "Show me your nose," or "Put your finger on your nose," and follow this by repeating the same order for the eyes and the mouth. Sometimes the child does not comply because he is distracted, or because he is timid and too bashful to do that which is desired, but usually, with a little insistence, a response is secured. Sometimes a child shows his nose by thrusting it forward, without making any hand movement, or shows his mouth by opening it, as would an animal. This is, in fact, an animal stage, when the hand is still a paw, and not an organ used for significant or expressive movements.

As this test and the following ones are especially applicable to very young children, it is necessary that the experimenter be warned that many very young children, especially those of three and four years, remain voluntarily mute and motionless when questioned. Some consent to do little acts, such as showing where the nose is, but they refuse to speak; speech seems to require a greater effort than gesture. The directors of the Ecole maternelle can ahways point out children who, in class, never answer the teacher, sometimes even after two years of attendance; the majority of these mutes chatter away with their comrades; they are mutes only in 
class. Others, fewer in number, never speak in school either to teachers or comrades; but their parents testify that they talk at home. Teachers experience great difficulties in the effort to encourage sociability in such children. We recall a charming director who told us that for a period of two years all her efforts to make a certain little boy of four years speak were in vain; she finally succeeded, thanks to the help of a cat. One day she left the child alone playing with the cat, and gradually he began to talk to it. He said: "Good morning, Minet." The miracle was wrought, the child's tongue was loosed.

Imagine the difficulties of an experimenter who, wishing to make an examination of intelligence, is met by such a silence. What should be done? The help of the teacher is often useful. If she is intelligent, she knows what to say to her children to reassure them and arouse their courage. A caress to one, a reprimand to another, and all goes well. We have seen children who persistently refused to perform a test, declaring themselves unable; for example, they stood before some ribbon, refusing to make a bow or even to touch it; after a sharp reprimand they decided to work and produced a beautiful rosette.

II. Repeats two digits.-The repetition of numbers requires very nearly the same sort of effort as the repetition of sentences; however, as numbers have so much less meaning than sentences, they make little appeal to the intellect or interest, and therefore require a greater effort of attention. As a result, a child of three years who can repeat a sentence of six syllables can repeat only two digits. The association of ideas triples the memory span.

The experiment is performed as follows: The experimenter tells the child to listen, and begins by pronouncing a single digit. The child repeats it. Two digits, not consecutive, are then given; for example, 3-7, or 6-4. They should be pronounced slowly, an interval of half a second being 
allowed between the two. If an error is made, or some speech defect prevents the understanding of the repetition, another beginning should be made. It suffices that an exact repetition be made once in three trials. When the repetition of two digits is possible, three are tried, always at the rate of two per second, and always avoiding special emphasis; one success in three is still sufficient. Many children of three years who repeat two digits with ease are incapable of repeating three; one additional digit greatly increases the difficulty. When the repetition of three digits is possible, five are tried, always under the same conditions of rate and of pronunciation, and still considering one success in three suffcient. It proves much more difficult to repeat five digits than three. A great variety of errors are made by the children; first a complete silence, then a sort of vagueness and uncertainty of pronunciation; then a partial repetition in which only the last numbers and sometimes only the last number are given; next a tendency to give numbers which have not been mentioned. Such numbers are not a chance choice, but depend upon the natural order of numbers; thus, a subject to whom one gives the series $5-8-2-7-4$, says $5-8-2-3-4$, the two naturally calling up the three. Sometimes the phenomenon is still more clear, so striking that it implies a very feeble critical sense; as when a child who has completely forgotten the figures 0-8-2-7-9, says 1-2-3-4-5-6.

III. Enumerates objects in a picture.-Pictures are invaluable in the examination of children. The most inattentive child brightens up when shown a picture. It is an almost sure road to their confidence. Pictures may be used for many purposes; the child may be asked to point to the various pictured objects as the examiner mentions them; if he succeeds, he has the ability of immediately associating the auditory impression of the word with the object for which it stands. In this test we use the picture to make the child talk. We reverse the former method, having the child name the objects which he sees pictured before him, thus testing his ability to recall the name of an object which he sees. It is much more 
difficult for the child to pass in thought from an object to its name than from a name to the corresponding object. Before the child is placed a picture on which appear many objects with which he is familiar and which are interesting to him. He is then asked to tell us what he sees. He thus has the opportunity to use what language ability he may possess in expressing his ideas, and also the liberty of choosing those objects which please him most; the response will show us what interests the child and will also give us an idea of his mentality, of his manner of perceiving, interpreting and reasoning. The test has the remarkable advantage of serving as a diagnostic test of three different intellectual levelp The responses of the subject indicate whether he is a the level of three, seven, or twelve years. There are very few tests which yield such rich results. If we add that the test is one of those which amuse children the most, and is most useful in combatting the persistent silence of the little ones, it seems reasonable to conclude that we have found by chance a test of exceptional value. We place it above all others; and were we limited to one test, we would without hesitation choose this one.

We use three engravings which are reproduced in the appendix (Fig. 1, 2 and 3). If care is taken other analogous pictures may be substituted, but ours have a certain standardized difficulty, and therefore it is better to use them; all of ours contain people and suggest a story; these are the essential conditions. The engravings are mounted on cards, and are presented one after the other to the child, who is asked: "What is this?" Then, if the child is very young, he may respond naively: "It is a picture," or "It is a postal card." The question is then put in another form: "Tell me what you see there." It is very rare, quite exceptional, for the child to remain silent. Even at the age of three they are curious about the picture, and this leads them to reflect, as it does the older and wiser. The responses obtained by us are of three distinct kinds, each of which is characteristic of a different intellectual level. 
1. Enumeration.-These responses are the most elementary. The child enumerates separately the persons and objects which he recognizes in the picture, without establishing any connection between them. He names only common objects. In the most elementary form the responses are limited to the following: "a gentleman," "a man," "a woman," "a papa," "a carriage," "a little child." Some very young children use the article the, "the child," "the gentleman," "the woman." Sometimes, instead of naming people, the child chooses objects: "a bed," "a table." Notice it is the objects which are named and not the action. When shown the second picture a child of three will say: "a gentleman;" we never found one who sal. "he sleeps," or one who mentioned the action or descrined tre people. A child of three who would make such a remark would be much in advance of its age. At three years one is at the stage of recognition, or identification of objects; this is the important, fundamental work in the perception of the external world, in comparison with which all other processes of perception are only complementary. The degree of development of this fundamental process of identification shows itself in different ways; it is revealed by simple addition; the number of objects named increases; instead of one-two, three or four are named. When several are mentioned, the question of order arises. Most often with our three pictures the children mentioned the people first; but there were exceptions to this rule, and sometimes inanimate objects were first chosen. Thus, for the third picture: "two tables, a chair, a bed, a man," for the second picture: "a man, a woman, a bench," for the first: "a wagon, a gentleman, a bucket, a basket." Sometimes a curious error is produced by suggestion when using the first picture; noticing the wagon, the child says: "a wagon, a horse."

In a third variety, scarcely superior to the preceding, the objects are not named separately, but are related, in a very feeble manner it is true, by the conjunctions, and, with or and then. "A gentleman and a lady," "a wagon, and then a gentleman," "a gentleman with a lady." 
This type of response by enumeration is sometimes met with in older children who are retarded; it therefore is distinctly characteristic; there is a persistence of the form of enumeration, but it is used in conjunction with a large number of words, while the enumeration of a young and normal child is, on the contrary, very brief. This difference is explained by the fact that the retarded child of eleven years who is still at the mental level of a child of six or seven years, has the advantage over the latter of a much longer experience; having lived longer, he possesses a larger vocabulary. Example: Mad....a child of ten and a half who has an intellectual development of seven years (we explain dater how we fix the intellectual level with such precision) gave as the following enumeration in reference to the first picture: I see an old man, and then a child, there is a flood, there is water, a wagon, a basket, a brush, a pail, two wheels, a carpet. Another example of fluent enumeration, still more characteristic, is found in the following response of Lau...., child of thirteen years, four years retarded intellectually: A gentleman, a wagon, a child, a pail, a basket; behind, a piece of wood; behind, some rocks.

In all cases the most frequent type of response is credited.

2. Description. This is the level of seven years, while the response by enumeration corresponds to the level of three years. The difference is great. Here the characteristics of the people and the nature of the objects are mentioned; moreover, attention is called to their relations; with the result that phrases are substituted for simple words.

Print 1: There is a man and a little boy, who are pulling a wagon.

Print 2: A man and then a woman, who are asleep on a bench.

Print 3: There is a man standing on his bed to look out of the window. A man looking at himself in the glass. 
3. Interpretation. The meaning of the picture or the nature of the people is told either by a brief word or by an explanatory remark, and often there is even an emotional note, of sadness or of sympathy; it is possible that this emotional note exists with children who make a more simple response, but they are unable to express it. We call these responses interpretations, because they go beyond the visual impression; there is a real effort to explain the situation depicted. Examples:

Print 1: A rag picker.-A poor man moving.-There are some people moving without paying the rent.-There is a man in trouble.

Print 2: They are in want.-A miserable creature.-They are poor creatures sitting on a bench, and they have no home to sleep in.-It is night, they are poor and needy.

Print 3: A prisoner.-That represents a prisoner, a man who is in prison, who climbs on his pallet to look through the prison window which is barred.

If the words moving, miserable and prisoner are used in the descriptions, it is safe to conclude that the pictures have been interpreted. The hierarchy which we have introduced in classifying our responses can not be defended philosophically. An observer, hostile to all theory, would claim that descriptions are superior to interpretations because they are less subject to error; they state exact facts, adding nothing, while interpretation is conjecture, and may be purely fanciful. "Hypotheses non fingo," such a critic will say. Such discussions will arise. The point which we have made as a result of our studies with children, certainly merits use as an argument in the debate. As only the older children use interpretation we conclude that a higher intellectual level is necessary for its production. But the question is a complicated one; it is necessary not only to take into account the intellectual level, but also the possible deviations and errors peculiar to the same level. We recall having shown our pic- 
tures to an adult, known to be rather foolish. He made many interpretations, but most peculiar ones. For example, the first print inspired the following response: It is a scene taking place in the month of February. Let us analyze this conjecture. It is evidently an interpretation, but an altogether gratuitous one, which it is impossible either to confirm or to refute. The scene could just as well be placed in October, November, December, January or March. Why, then, this precision, which is at the same time useless and unjustifiable? This response is an interpretation, and in our classification it is superior to the descriptive response of a child of seven years; but in addition it betrays a lack of judgment; this lack of judgment is independent of the hierarchy of responses.

IV. Gives family name.-We now ask for a piece of information which a child of three certainly should possess; its family name. All children of this age know their first names, that goes without saying, or the pet name by which they are usually called; but the family name is not so familiar. However, they are expected to know it at school, and at the "Maternelle" they are habitually called by their family name.

The child is asked: "What is your name?" If he only gives his first name, the last is insisted on. "Roger? And then? And then what? etc."

It sometimes happens that the child gives a name different from the one under which he has been entered. This often happens with illegitimate children, and also when a child's mother has had several husbands and changed the child's name with her own.

If a child fails to give his family name, he is asked what his mother's name is. But this question is too difficult for three years, and the answer: "Her name is Mamma," cannot be considered a bad response for this age.

V. Repeats a sentence of six syllables.-After the comprehension of words, the next step in the development of 
language is not, as one might think, the verbal expression of thought, the naming of desired objects, but a repetition of words heard. It is easier, apparently, to echo a word than to use it independently - to pass from an idea to a word. We have observed this to be the fact with both imbeciles and normal children. A child of three, if he will make the effort, can easily repeat a word or a phrase; it is sometimes difficult, however, to decide whether the repetition is correct, because such young children have a natural defect of pronunciation which we will call simply a vagueness, a baffling quality; this is produced by a stumbling over the words and by their incomplete production. This vagueness is not an actual defect of pronunciation, due to anatomical or functional defect of the speech organs; it is simply a lack of skill; therefore, this vagueness must be taken into consideration in the diagnosis of the intelligence. On closer study we find that this awkwardness, this lack of skill, is not limited to articulation, but appears also in the choice of words and in the formation of sentences; for the adult forms are substituted more childish ones.*

For this test the following sentences are used, which have been chosen with the intention of using words very easy to understand:

I am cold and hungry. (6 syllables.) lables.)

My name is Gaston.... Oh, the naughty dog. (Io syl-

Let us go for a long walk.... Give me the pretty little bonnet. (I6 syllables.)

These sentences should be given expressively. No error is allowed in the repetition. If the child is timid and remains silent, shorter sentences should be used; we use the following:

*TRANSLATOR'S NOTE.-The examples in the text are omitted here because they are applicable only to the French language. Analogous mistakes made by American children are the confusion of the gender and number of pronouns and misplaced prepositions. 
Papa. (2 syllables.)

Hat. Pair of shoes. (4 syllables.)

I am cold and hungry. (6 syllables.)

I have a handkerchicf with me. (8 syllables.)

My name is Gaston. Oh, the naughty dog. (Io syllables.) lables.)

It rains in the garden. John has finished his task. (12 syl-

We are cnjoying ourselves greatly. I have caught a mouse. (I4 syllables.)

Let us go for a long walk. Give me the pretty little bonnet. ( I6 syllables.)

Charlotte has just torn her new dress. I have given two cents to that beggar. (I 8 syllables.)

It is not mecessary to hurt the birds. It is night, all the world rests in sleep. (20 syllables.)

A child of three can repeat a sentence of six syllables; it cannot repeat one of ten.

\section{CHILDREN OF FOUR YEARS.}

I. Gives own sex.- “Are you a little boy or a little girl?" This is the very simple question which we use. Three-yearold children do not all succeed in answering it. The correct response is: "A little boy" or "A little girl." Sometimes the child merely says yes or no. It is then necessary to ask two distinct questions: "Are you a little boy?" "Are you a little girl?" It takes very little to confuse at this age.

Children of three years may fail, but a normal child of four always answers this question of sex correctly. However, we expect a great change in the mental state to take place between the third and the fourth year.

II. Names key, knife, penny.-Another test of spoken language, but differing from the language suggested by pictures; it is much more difficult. In a picture the child chooses what he wishes to name, and names those objects which he 
recognizes; here we choose the object; that is, we force him to name some one object and no other. These are differences which on a priori judgment seem insignificant; but in reality they are great. The proof is that the majority of children of three years succeed with the picture test and fail when asked to name the objects. It is true that the objects are a little less familiar than men and women, for which children show a preference in the picture test. The child is shown successively three familiar objects-a key, a closed knife and a centand is asked: "What is that? What is it called?" The key is properly named, sometimes with a defective pronunciation. The penknife is usually called a knife, and the penny, pennies. Such little errors are excused, but it is necessary that the names of the objects be known.

In our choice of objects we are guided by the fact that all experimenters are likely to have a penknife, a key, and a penny about them, and our endeavor is to use as little special apparatus as possible.

III. Repeats three digits.-This test is conducted in the same manner as that calling for the repetition of two digits. No further remarks are necessary.

IV. Compares two lines.-Here are some tests which present unexpected difficulties. An imbecile who understands when one says: "Go and open the door," when the words are not supplemented by either a gesture or a glance in the right direction, is unable to compare two lines in regard to their length. Does he see that the two lines are of unequal length? It is quite possible. If it were two biscuits, would he take the longer or the shorter? That is yet to be determined. But he does not comprehend the words: "the longer;" he does not understand that he is asked to compare two lines, and, pointing at random, he foolishly puts his finger on the space between the two lines. The child of three years does the same thing. Not until its fourth year does a normal child succeed with this test. 
The test is conducted as follows: Two lines, one 5 centimeters in length, and one 6, are drawn with ink on white paper; they are parallel and separated by a distance of three centimeters. The lines are shown to the child: "You see these lines. Tell me which is the longer." No hesitation is allowed. Sometimes the child puts its finger between the two lines. That is sufficient, unless the child corrects himself, for any hesitation is considered a failure. The test is a short one, easy to perform and easy to interpret.

\section{CHILDREN OF FIVE YEARS.}

I. Compares two weights.-This is a comparison similar to that of the lines; but one judges the lines at a glance, while it is necessary to take the boxes in the hand and heft them; often they are taken in the same hand and compared successively. Conclusion: Very few children younger than five succeed with this test, while those of four succeed in comparing the length of the lines.

Four boxes are used, the same in appearance and volume, and weighing respectively 3 grams and 12 grams; 6 grams and 15 grams. First, the two boxes of 3 and 12 grams are used. They are placed on the table before the child, with a distance of 5 or 6 centimeters between them. The child is asked: "You see these boxes. Tell me which is the heavier." The correct response consists in taking the boxes and hefting them one after the other in the same hand, or at the same time in two hands, and pointing out the box which weighs 12 grams. To make sure that the choice is not the result of chance, the two boxes of 6 and 15 grams are then presented; then the first two boxes are again used and the results compared. If there remains the least doubt, repeat the test. A very young child behaves differently. When asked the question, he responds at once by pointing, quite at random, at a box, without thinking of weighing it. We overlook this naive error, which may sometimes be explained by thoughtlessness, and sometimes by suggestibility or a desire to please us, and we say to the 
child: "No, that is not the way. You must take the boxes in your hands and weigh them." This supplementary instruction is sufficient to orient most subjects; so much the worse for the others. We have observed curiously the errors made by these last. Here are some of them: To lift only one box and declare it to be the heavier; to place the two boxes side by side in the same hand and declare that one is the heavier; in this case the weighing is much more difficult without being impossible; finally, to place them one on top of the other in the same hand. This is still more defective as a method of weighing; however, it is still possible to detect the difference in weight.

This test includes two quite distinct operations; one consists in understanding that the weights of the two boxes are to be compared, and the consequent act of comparing them; the other consists in appreciating the difference in the two weights. The first operation is much more difficult than the second; one can even say that it depends on the general intelligence and presupposes a high intellectual level, while the second depends on the much more simple faculty of feeling a difference in weight, and exists at a much lower intellectual level, perhaps one of only two years; this is proven by the fact that when a child, in spite of all possible explanations, fails to take the weights and compare them, it is often sufficient to place the weights one in each hand and ask him which is the heavier to secure from him the correct gesture. The awkwardness with which a child takes the weights, hefts them and compares them, and the surety with which he shows that he feels the difference in weight, is always an interesting contrast.

II. Copies a square.-This is the first time that we have put a penholder into the child's hand.

A square with a diameter of from 3 to 4 centimeters is drawn with ink, and the child is asked to reproduce it, using pen and ink. The use of pen and ink increases the difficulty of the task and a pencil must not be substituted. Young sub- 
jects reduce the size of the figure; this is of little importance if it is recognizable. We give (Fig. 4 of the Appendix) some specimens of reproduction which we consider as tolerable $(1,2,3)$ and other reproductions which seem to us so defective that they constitute a failure $(4,5,6)$.

III. Repeats sentences of ten syllables. See above.

IV. Counts four pennies.-The objection is made that enumeration is a test of scholarship which implies instruction rather than intelligence. The objection is just; but where is the being so deprived of tutelage that no one has ever taught him to count? We have studied many imbeciles in the asylums; all those who have sufficient intelligence to count have learned to do so. In spite of the compulsory education laws, there still remain many illiterate people; it is said that there are more than five per cent, among the soldiers, but has one ever met an individual who has never learned to count if his intelligence permitted it? Such an one would be very rare.

The study of the act of counting is very complicated, and it will be seen by what follows that this little test, which is of great practical importance, appears many times in our Scale. To be able to count it is necessary to know many things; first, it is necessary to be able to recite the numbers in serial order correctly; it is necessary, also, to be able to apply each number to a different object. We have not used as a test the simple recitation of the figures because this is an affair of memory; we prefer the act of counting, which presupposes some judgment. We ask the child to count four pennies.

Four pennies are placed on the table; they are placed in a row, not in a pile. The experimenter says: "See these pennies. Count them. Tell me how many there are." Some children, without counting, answer at once, giving any number at random. Whether it be correct or not, such answer should not be noted. The child must be made to count them, 
pointing with his finger. Any error constitutes a failure. At three years a child cannot count four pennies; at four years nearly half the children succeed; at five years only retarded children fail. It is truly a test for five years.

$\mathrm{V}$. Game of patience with two pieces.-This is a game demanding an arrangement, a combining of pieces, which pleases children; they often amuse themselves at school by constructing objects with cubes. It is a game and at the same time a work for the intelligence, operating with the given material, some sensations and some movements. If the operation is analyzed, it is found to consist of the following elements: 1. To keep in mind the end to be attained, that is to say, the figure to be formed; it is necessary to comprehend this end; it is necessary also to think about it, not to lose sight of it. 2. To try different combinations, under the influence of this directing idea, which often guides the efforts of the child, though he be unconscious of the fact. 3. To judge the formed combination, compare it with the model, and decide whether it is the correct one.

$t$ is at once seen that the game of patience can be complicated so that its difficulty may be varied at will. There are some games which a child of five can solve, and others which try the skill of an adult. We commenced by choosing a very difficult game, and we think that it will be of interest to explain why we abandoned it; it was because success in it is too much a matter of chance. If in a game consisting of a dozen pieces of card, the subject was fortunate enough to pick up at once two or three cards which belonged together, the completion of the task would be easy; on the other hand, were he not so fortunate, the problem would be much more difficult. It also happens that the number of successes are altogether independent of age. This objection, which obtains with some kinds of tests, led us to give up this type of game.

That which we finally adopted is much more simple, it consists of two pieces only and is adapted to children of five years. 
An oblong card is cut along the diagonal, making two triangular pieces. An intact card is placed on the table, and by its side, nearer to the child are placed the two triangular pieces, arranged so that the two hypotheni form a right angle, and we say to the child: "Put these two pieces together, so as to make something like this." (This refers to the intact card which lies before him.)

Children of four years do not succeed in forming the oblong. Only one-third are successful. As for the others, they do not understand what is required, and they move the cards about at random; fail to touch them at all; put then together incorrectly; place them side by side but not facing each other ; cover one by the other; or finally form a figure which has nothing in common with the model.

At five years there is a decided progress; we found that scarcely one child in twelve failed. The others performed the task well.

Some precautions must be taken with this test. IVe point out the three following: 1. Some little ones do not wish to take the trouble to move the cards or even to touch them. It is then necessary, without giving any precise suggestions, to scold them a little in order to arouse them from their apathy. They do not succeed beyond those who fail to bring two cards together, in whatever form, or those who cover one piece by the other. 2. In this test one should iry to prevent the child from turning one of the cards over when he is bringing them together, for if he does it will be impossible to form a figure like the model. If he inadvertently turns the card and is unconscious of it, it is permissible to begin again, or to consider the test passed if the two cards are so placed that their longest sides are in juxtaposition. 3. When the child makes a combination he is apt to stop and turn to the examiner for an assurance that it is correct or otherwise. Our attitude towards his work then determines whether he will remain content with it or make another effort. It is 
essential that no opinion be expressed; that we wait, and wait in silence.

\section{CHILDREN OF SIX YEARS.}

I. Distinguishes between morning and evening.-The perception of time is a slow development with a child; for a long time yesterday and tomorrow are confused. The distinction of our test is brought out by the following question: "Is it morning or afternoon now?" Some children give a chance answer, others simply say "yes"; not until the age of six is a child absolutely sure whether it is morning or afternoon. Before reaching this age they can often tell, however, whether they have or have not eaten their mid-day meal.

Apropos of this finding, our readers will doubtless make a remark which they will often repeat in reading the tests which follow; it is that children are much less advanced, much less intelligent than they are thought to be. We answer that an examination such as ours, a rapid one which takes the child by surprise and obliges him to tell and tell immediately, what he knows, tends toward a low grading of the child. But even taking this into account the preceding observation still holds. One expects, we ourselves expected, more brilliant results. We would have judged that children could distinguish between morning and afternoon long before the age of six. It is a distinction which appears so easy! Think of the fact that six-year-old children are the oldest in the "maternelles" schools. Recall that the programs of these schools provide for the teaching of history and of geography; "the principal irregularities of the earth's surface, brief biographies from national history," read the rules of the schools "maternelles" of the department of the Seine. Is it not rather ridiculous to talk about national history to children who cannot yet distinguish between morning and afternoon?

II. Defines in terms of use.-Thus far the verbal responses required from the little ones have all been short; a 
word or two sufficed. Now we are about to ask for a phrase, for an object can not be defined without forming one. The definition is not solely an exercise and test for language; it serves to show us the idea which a child has formed of an object, the manner in which he has conceived it, the point of view which is to him the most interesting.

The child is asked successively: "What is . . . . . . 1-a fork? 2-a table? 3-a chair? 4-a horse? 5-a mamma?" These objects have been chosen from many because we have found that they lend themselves to a useful classification of responses.

It is not easy to perform the test with very young children. They often respond by stubborn silence. We have said to them in vain: "You know well what a table is, a chair, you have used a fork," and concluded a little rashly, that knowing these objects they should be able to tell what they are; this does not always succeed in breaking their silence; some point to a nearby table and say, "It is that."

If our purpose was a study in general psychology a good classification of responses could be made. For the purpose of diagnosis we have only three distinctions to establish:

1.-Silence, simple repetition, designation by gesture. We have just given an example of designation by gesture. As to repetition, it is self explanatory; it consists in repeating the given word. "What is a fork?"- "It is a fork." Sometimes the child takes it into his head that in this way he will avoid all difficulties, one can be certain that he will use it for the whole series of definitions; he has found a path of least resistance and he is faithful to it. There is not the least spirit of malice. The child believes that he has responded seriously and suitably to the questions asked him, and he even feels quite pleased with himself. Do not undeceive him. With a perfect optimism say to him: "That is very good," and mark the result as being a complete absence of response. This result is not extraordinary in psychological experimentation; for 
example in the experiments on the association of ideas with young children and defectives the subjects frequently simply repeat the stimulus word.

2.-Definition in terms of use only.-Examples: Horse, it is to pull carriages, -it is to run, it is to sit on. The frequent visits to the butcher shops where horse or mule meat is sold, which are customary among the class of people to which our children belong, explain the following response: "Horse, it is to cat." We asked the child whether he ate the meat of the horse, and he said, "Yes." Fork, it is to eat-to eat with. Table, it is to eat on-or, a table is used to eat on; it is the table where the plates are put,-it is where we eat. Chair, it is for us to sit on,-it is to sit on,-it is used to sit on,-it is that which we sit on. Mamma, she is to take care of little children,--she is to kiss,-she sends on errands,--she cooks the food.

All these answers are clearly infantile, not only in their incorrect form, but also in their conciseness, and finally in the state of mind which they reveal; scarcely any children of seven years are exclusively utilitarian in their definitions.

3.-Definition in terms superior to use. These are so varied in form that it is impossible to cite all the varieties; but this is unnecessary for the essential point is not the character of these definitions, but the fact that they differ from the definitions in terms of use. The distinction is made difficult by certain responses in which the subject is chiefly concerned about the use of the object but describes it in less infantile terms than those quoted above. Examples: Table -It is an object used for eating, or it is an instrument for eating; it is a utensil for cating; it is a piece of furniture for eating. Horse-It is an animal which pulls carriages. Mamma-She is a woman who cooks the food; she is a woman who takes care of the children. The use of the expressions: It is an object, it is an animal, it is an instrument, it is a thing, indicate that the definition is less infantile. Definitions learned at school are also given, they are curious in their 
brevity; a table, it is a thing; a horse, it is an animal, it is a domestic animal; a mamma, she is a person; she is a woman. In other cases children try to describe the object; a fork is a little fork with four points; a table, it is a board with four feet; a horse, that has four legs; a horse that runs, that bites, etc. Or still another series given by a child of nine years: A fork has four prongs, - a table has four legs,-a chair has four legs, - a horse has four feet,-a mamma has two hands and two feet. Older children think of the character of the object and of what it is composed: A fork is made of copper; a fork is a white metal; a table, it is wooden; a chair, it is some pieces of wood and some straw; it is of waxed wood; a horse, it is meat, etc. Another point of view is the grammatical: Table is of the feminine gender, chair also; horse is of the masculine gender. We think it useless to give examples of more intelligent responses, because this test occurs in our scale at the ages of six and nine. The intellectual development of these two ages can be distinguished by the kind of definition give by the child. The value of the definitions is judged by the character of the majority of the definitions. Five are required of each child. We note the character of responses common to three of them.

Half of the children of four years of age define in terms of use only; the proportion is a little greater for the five-yearold group; and practically all of the six-year-old children use this form. We have found that not until the ninth year are the majority of definitions given in terms superior to use.

III. Copies a lozenge.-Hospital experience suggested this test. We were surprised to find imbeciles who could copy a square and yet failed in the attempt to copy a lozenge. These figures are not very different in form, but the direction of the lines of the lozenge is much more difficult to reproduce. We found the same true of the children in the regular schools; at five years of age a child can copy a square; not until six can he copy a lozenge; and even at seven one-fifth of the children fail. At six years one-half fail. In the appendix we 
give a drawing (Fig. 5) which contains examples of good copies $(1,2,3)$ and of bad copies $(4,5,6)$, so that all may adopt the same criteria.

IV. Counts 13 pennies.-The difficulty of counting is so much increased by the addition of objects that it is necessary to wait until the sixth year before requiring a child to count thirteen pennies. The thirteen pennies are placed in juxtaposition, not one upon another. The child is instructed to point to each with his finger and count aloud. It is necessary that the solution thirteen be given; and sometimes this is not sufficient, when one feels certain that it is given by chance, or as the result of several errors. Three conditions are necessary to the successful solution of the test: 1 . That the subject knows how to count to thirteen, and makes no mistake in the enumeration; one can imagine the many errors possible in this process. 2. That the subject touch a piece and at the same time pronounce a number; for the correspondence of the pointing and of the counting is often at fault. There are, for example, young children who name only one figure while touching, by two movements, two different pennies. As a rule, the hand moves more quickly than the speech. 3. That the subject forgets no piece and that he counts no piece twice. This last error, which can be avoided only by employing some method, can be committed even by adults. We have seen some children of six years who took the precaution to remove each penny as they counted it. This is the perfection of method; these are the good traders.

At seven years there are no failures.

$\mathrm{V}$. Compares faces from the aesthetic point of view.-It is incontestable that all young children have the sense of the beautiful, and that it can be brought out by presenting the problem in a simple form; for example, as a comparison, a choice between two faces, one of which is pretty, the other ugly; it is necessary that the contrast between the two faces be very great. This question is very interesting from the 
philosophic point of view, and clearly shows that there is no faculty of the adult which does not exist to some degree in the child.

This is our method. We use six drawings (Fig. 6, of the Appendix) representing heads of women; some are pretty, the others are ugly or even deformed; the faces are compared two at a time, and each time the child is asked: "Which is the prettier of these two faces?" The child must respond correctly all three times. Care has been taken to place the pretty face sometimes to the right, sometimes to the left, in order to avoid the possibility of a 'success due solely to the habit of pointing every time to a picture on the same side. It is very necessary to guard against this automatic tendency to go in the same direction; it is very common with children. At six years children compare the three pairs of faces with ease; at five they are not very successful, one-half only giving at this age correct answers.

\section{CHILDREN OF SEVEN YEARS.}

I. Right hand, left ear.-Another notion gained through instruction, but so easily acquired that the lack of it is conspicuous. The child is asked: "Show your right hand," and this done; "Show your left ear." The last question is almost a trap, for having commenced by asking for the right hand, a tendency is created to show the right ear.

Sometimes the child shows both hands; or rather, he uses one hand to show the other, but the gesture is so obscure that one can not tell which is the hand indicated. The question is decided by telling the child to raise his right hand. The children may be divided into three categories according to their manner of response: 1. There are some who have absolutely no knowledge of left and right. They present the right hand because there is a tendency to use it rather than the left; then they touch the right ear. We will not pause to consider those who understand still less, do not know where their ear is. 2. There are those who have a notion of right 
and left, but they are not yet sure. They present the right hand and touch the right ear, then correcting themselves touch the left ear. 3. Finally, a third group is formed by those children who, without error and without hesitation, present the right hand and touch the left ear. We consider successful the children of the two last groups, those who hesitare and correct themselves as well as those who do not hesitate nor have to correct themselves. But it is important that the experimenter watches himself and gives no suggestion; it would be very natural to do so. It is evident that if, when the child touched his right ear, one said: "Are you sure of it?" or even looked disapproval of the gesture, the child would be led to touch the left ear, for, if it is not the one, it is the other.

II. Describes a picture.-We have seen that at three, four and five years enumeration is the rule and description quite unusual. At six years a very small number of children, scarcely a sixth, try description. At seven years such progress in language has been made that description has become quite general; there are very few exceptions, and this test shows the enormous advance from the point of view of language which takes place between six and seven years.

III. Executes three commissions.-Among the people quite young children are sent on little errands to the stores, to buy milk, bread, to the butcher's more than all, and to bring home a bottle of wine. Physicians who frequent the clinics for retarded children recognize that these cliliren, though they can be trusted to perform one commission, can not be given several at the same time. The mothers often tell the doctors of this interesting peculiarity. Here is the series of commissions which we give with the directions given with them: "Do you see this key? Go and put it on that chair, there" (pointing to the chair). "Then close the door. After that you will see a box on a chair near the door. Take the box and bring it to me. First, put the key on the chair; then close the door; then bring me the box. Do you understand? 
Now go!" Very often the child only performs two of the three commissions, or on reaching the door closes it on himself. Some are satisfied with themselves and others realize that they have forgotten something and remain thoughtful. The test is passed successfully when all three commissions are executed spontaneously without the necessity of such help as, "Well, and now? You forget something, etc." It is evident that the commissions may be varied a little to suit the surroundings. They should, however, always be simple and easily executed. Nothing that would intimidate the child should be asked. If the experimenter placed his hat on a chair, it would not do to use it in one of the commissions as an object to be moved, for many a child would noi dare to touch it.

IV.* Counts nine sous ( 3 single, 3 double).-On a corner of the table are arranged side by side three single and three double sous. The subject is shown the money and directed: "Count that money and tell me how much is there." Some children do not touch the money; it is necessary to find some way to induce them to count. The difficulty of the test lies in the mixing of the single and double sous. No error is allowed. The slightest error constitutes a failure; and the child should not be allowed to repeat the test. The only precaution necessary is to arrange the money so that all the pieces are visible. The test takes from 5 to $10 \mathrm{sec}-$ onds. If it takes longer, there is a strong probability of a failure. It is useless to wait 15 seconds. Children behave in three different ways: 1 . They count exactly, in the following manner: 1-2-3-5-7-9; that is to say, they add 2 for each double sou. 2. They count exactly, but for the double sous they do not add by twos; they say: 1,2,3,--then 4 and 5 (for

*TRANSLATOR'S NOTE.-As there is no two-cent piece circulating in American currency, Dr. Goddard has substituted one and two-cent stamps for the single and double sous. The test seems to be an equivalent one, provided the experimenter makes sure that the child knows the value of the stamps before he gives the test question. 
the double sou), 6 and 7 (for the second double sou), 8 and 9 (for the third). 3. They count the double sous as single sous. The last is a failure. At seven years there is already a great majority who succeed. All succeed at eight years. This is, then, rather a test of the transition period between the two ages.

V. Names four colors.-Tests with colors can be indefinitely multiplied. We have chosen the fundamental colors, red, blue, green and yellow, and have omitted those the names of which are less familiar to children; for example, violet and orange. The test is not of the perception and distinction of colors, but the naming of them, which is quite different. Young children recognize, distinguish, and match the most delicate shades; they are quite equal to adults in color sense; it is the verbalization of this color perception, if one can so express it, which is defective with children.

Four pieces of paper, red, yellow, blue and green, respectively, and 6 by 2 centimeters in size (smaller pieces should not be used), are arranged on a piece of cardboard. Each color is pointed to in turn, and the child asked: "What is this color?" No error is excused. The least error is considered a failure. This test takes about six seconds.

\section{CHILDREN OF EIGHT YEARS.}

I. Compares two remembered objects.-This is a valuable test because it does not depend in the least on instruction, and brings into play the natural good sense of the subject. It consists in investigating whether the subject can, in thinking of two objects, distinguish a difference between them; the perception of a difference is in fact the habitual and the most natural result of a comparison. We prepare for the test by talking to the child as follows: "You have seen butterflies, you know what they are?-Yes.-And flies, you know them also?-Yes.-Are they alike, a fly and a butterfly?No.-In what way are they not alike?" This is not expressed in the best style, but it has the advantage of being easily 
understood. Similar questions are asked about wood and glass, and paper and cardboard. We always begin by asking the subject whether he knows the objects in question, and whether he finds that the objects "are not alike." Then attention is given to the response and above all to the value of the response. A mere naming of the object is considered insufficient. The child is asked: "In what way are the cardboard and paper not alike?" If the child responds: the cardboard, it evidently proves that he has not understood. A bad response, though somewhat better than a mere repetition, is: A fly, it is a fly. More often the difference noted is one of size: The butterfly is larger, and the fly is smaller; the cardboard is larger; the wood is larger. Often details are noted: The butterfly has the largest wings-the butterfly has white wings-the butterfly is yellow-they are not the same colorthe fly is black, the butterfly is many colored-it is that butterflies fly on the flowers and flies fly on the food-paper is soft, cardboard is harder-cardboard does not tear-wood does not break-wood is not transparent-glass is used for windows, and wood is used to make floors.

For success, two at least of the three comparisons must be correctly given. To be considered correct the difference must be exactly given. It often happens that having found a differential character for the first pair, the subject repeats it for the other two; having said that the butterfly is larger, the repetition of this for the cardboard and the wood is not a sufficiently good response. It often takes a child as long as a minute to respond; so much the worse if at the end of this time the response is incorrect. At six years one-third of the children make the correct comparison; at seven, almost all; at eight, all.

It is very difficult to distinguish between the intellectual levels of seven and eight years, and we use some tests depending upon instruction, introducing them because they are also valuable as tests of intelligence.

II. Counts from 20 to 0 .-This is partly a test of school 
knowledge; one must have learned to count to be able to reverse the process. We say to the subject: "Will you count from 20 to 0 , descending?" If he does not understand, we add: "Count this way: 20,19,18-" but we do not proceed any further. Some children do not know how to count in this way and will not try. Others, obstinately, in spite of the instructions, count in the usual way either at once or after having made an effort to count as requested: $20,19.18,17$, $19,20,21,22,23$, etc. Others understand very well in what way they are asked to count, but they avoid doing so by going back and counting up again to find each figure. Thus, being at 15 , they count rapidly $1,2,3,4$, etc., as far as 15 , and find in this way that 14 precedes 15 . The method is betrayed by the words murmured by the subject, and by the time consumed in thinking of each succeeding number. All the responses so far described are considered failures. To be considered correct the process of counting must not take more than twenty seconds, and there must be no more than one error (omission or inversion).

III. Indicates omissions in pictures.-Four pictures are shown successively (Fig. 7, Appendix); in one an eye is lacking, in one the nose, in one the mouth, in one the arms. The child is asked each time: "What is missing in this picture?" Often the child does not answer, or if he does, makes some incorrect remark. For the first picture which represents a head he will say, for example, that the neck is missing, or the stomach, or the ears, or even the legs or the feet; and having thought of this response, he does not fail to repeat it for all the other pictures (automatism and repetition). All these statements are true, but they do not fulfill the requirements of the test-to show what the picture lacks to make it complete. Three correct answers are required.

IV. Gives the day and date-Four facts are required in answer to this question: the day of the week, the month, the day of the month, and the year. In this connection we wish to make a remark: We found that in the schools "ma- 
ternelle" a language lesson is given each day at the opening of school, in which the day and date are taught. The children are told the day, date and year, and then made to repeat it. However, not one child in the school was able to give us the complete information, nor one the name of the year alone; for the month many answers were given, January, even when it was in reality February 8th. Referring to our Scale, it will be seen that the complete idea is not attained until the age of eight. The great majority of children do not possess it until they reach this age. These findings lead us unexpectedly to an interesting conclusion on precocious teaching. The aim of instruction should be to aid the natural course of development of the child by hastening it a little; but it is a vain effort that gives it information three or four years beyond its level. In the present case this is demonstrated by the ignorance of these children of five or six years in regard to the facts taught them, facts that boys of eight are juct able to retain.

An error of three or four days is allowed in the day of the month. A very intelligent person might think it the 17 th of February when it is in fact the 14th., but he would scarcely make a mistake in the day, still less in the month, and never, unless he be suddenly amnesic, in the year. It is a curious fact that children fail most often to give the year. They give no year, they remain silent, for they do not know it. Perhaps a year is for them so great a lapse of time that they can form no idea of it. Then a glance at a calendar is sufficient to learn the day of the week and month, but not the year, which everyone is supposed to know. School calendars should make very conspicuous the number of the year.

V. Repeats five digits.-The method is described above. Three digits are used at four years; it is necessary to postpone increasing the number to five until we reach seven-yearold children, and still but three-quarters pass the test.

CHILDREN OF NINE YEARS.

1. Gives change from 20 sous.-This is a test which 
presupposes some little instruction; but it has so great a practical value that we use it.* We think it well to make the test under the guise of a game; we thus amuse the child and put him at his ease. Some money is spread out on the table; the nine pieces of current money $(0$ fr. $05-0$ fr. $10-0$ fr. $25-0$ fr. $50-1 \mathrm{fr} .-2 \mathrm{fr} .-5 \mathrm{fr} .-10 \mathrm{fr} .-20 \mathrm{fr}$.) - and in addition a sum of $0 \mathrm{fr} .65 ; 0$ fr. 30 in $0 \mathrm{fr} .10$ pieces and the rest in $0 \mathrm{fr} .05$ pieces. We say to the subject: "Would you like to play store with me? You be the storekeeper." Then show him the money: "Here is the money which you will use to make change for your customers." Then, showing him some boxes: "These are the articles which you will sell. They are boxes. I will buy this box. I will pay you four sous for it. Would you like to play?" The subject always consents, smilingly; the proposal pleases him. We then hand him a $1 \mathrm{fr}$. piece, saying: "I wish to spend four sous. Now, you give me the change." Then the hand is held out to receive the money. The only correct response is the following: The subject takes from the money $0 \mathrm{fr}$. 80 , offering it as change. Sometimes the child responds, "I should give you 16 sous," but does not give the exact number, giving instead 15 or 17 perhaps; this is counted an error. Of course, still graver mistakes, such as returning $2 \mathrm{fr}$. or $4 \mathrm{fr}$., are also considered failures. We had one subject, a school child of ten years of age, give us back $35 \mathrm{fr}$; ; this, however, is quite exceptional. It will be noticed that in this simple act of making change many variations occur. The quickest and most adroit at once pick out a 10 sou piece and add to it 6 sous. Sometimes, like real storekeepers, they say, " 4 sous and 10 , that makes 14 sous, plus 6 sous, that makes 20 sous;" sometimes they count by centimes. These are the bright ones. The others follow the suggestion of the 13 sous on the table; they begin by gath-

*TRANSLATOR'S NOTE.-As nearly an equivalent a test as can be made with United States Money is the problem of giving change from a quarter when four cents are spent. The change pile should consist of ten pennies, two nickels, two dimes, one quarter, one half dollar. 
ering up all the sous and counting them; then they are confused because this does not give them the necessary sum; they are obliged to begin again and take away some of the sous, replacing them by either a 10 sou or a 5 sou piece. The most ignorant, it seems, are attracted by the sous, which they can count most easily; one must be used to handling money to take at once the 10 sou piece, then the 5 sou, and finally the 1 sou. There are shades of difference in the performance of this test of which our method takes no account. Is the change given equal or not to $0 \mathrm{fr} .80$ ? That is all it notes. At most, in analyzing the results, one can call an error of one sou slight and an error of five sous great.

At seven years scarcely any children succeed in giving the correct amount of change when trying to take four sous from twenty sous. At eight years a good third succeed. At nine years they all succeed.

II. Defines in terms superior to use.-This test is explained above. At seven and at eight years one-half of the children give definitions of this kind. At nine years they all do.

III.* Recognizes all the pieces of our money.-These are the following: 0 fr. $05-0$ fr. $10-0$ fr. $25-0$ fr. $50-1$ fr.$2 \mathrm{fr} .-5 \mathrm{fr},-10 \mathrm{fr} .-20 \mathrm{fr}$.

The greatest difficulty is distinguishing between the $1 \mathrm{fr}$. and 2 fr. pieces, and the 10 and $20 \mathrm{fr}$. pieces. The various pieces are all placed on the table, and as each is pointed to in succession, the subject names it without touching it. Care should be taken not to show in immediate succession the $1 \mathrm{fr}$. and $2 \mathrm{fr}$. pieces or the $10 \mathrm{fr}$, and $20 \mathrm{fr}$. pieces.

Ve propose the following order: $0 \mathrm{fr} .10-2 \mathrm{fr} .-10 \mathrm{fr}$ 0 fr. $50-20$ fr. -1 fr. -5 fr. -0 fr. 25 .

*TRANSLATOR'S NOTE.-For the French coins we substitute in United States Money-a penny, a nickel, a dime, a quarter, a half dollar, a dollar, a two-dollar bill, a five-dollar bill and a tendollar bill. 
The coins should always be turned so that the child may see the effigy.

Frequently a child calls a 1 fr. piece $2 \mathrm{fr}$. and a $10 \mathrm{fr}$. piece $20 \mathrm{fr}$., or vice versa. These are due to slight confusion. Absurdities consist in inventing new pieces-3 fr., for example, or 15 sous. A curious error made occasionally is the confusion of 10 and $5 \mathrm{fr}$. pieces. The test should not last longer than 40 seconds. Finally, sometimes one suspects that an error is merely a chance one. One of our children, aged twelve, named all the coins readily excepting the $5 \mathrm{fr}$. piece, which he called $10 \mathrm{fr}$. We made no sign, but some time afterward we took the trouble to have him name again all the coins on the table. He repeated his error, and therefore failed. We cite this example to show that the results must not be taken automatically. It often happens that one suspects a chance error after later responses are given; it is then necessary to repeat the test and watch for a repetition of the error. In other terms, in spite of the system of marking which we have devised, we believe that the experimenter must judge of the responses which are made. Our method is not an automatic weighing machine, such as the scales of the railroad stations, which print an individual's weight entirely unaided.

IV. Enumerates the months.-The subject should name the months in 15 seconds without omission or inversion. We, however, allow the error of one omission or one inversion.

$\mathrm{V}$. Understands easy questions.-We give the text of the questions and some good and bad responses:

1.-What would you do if you missed a train? Correct answers: Wait for another train.-Take the next. Incorrect answers: I should try not to miss it.-Run after it.-Go home again.-Buy a ticket.

2.-What would you do if one of your playmates should hit you without meaning to do so? Correct answers: Do nothing to him.-Excuse him.-Pardon him.-Tell him to be more careful another time. Incorrect answers, which show that the 
reservation, "without meaning to do so," has not been understood: Tell the teacher.-Have revenge.-Punish him.

3.-What would you do if you broke something belonging to someone else? Correct answers: Pay for it.-Ask to be excused.-Replace it.-Confess it. Incorrect answers are generally unintelligible: I would have to make it pay. $-I$ would have to cry.-Go to the commissary.

It will be noticed that these three questions are easily understood and present no difficulties of vocabulary. It sometimes happens that children of only six answer them satisfactorily, but this is rare. At seven and eight years one-half of the children answer correctly; at nine years, three-quarters; at ten years, all. The test is considered passed correctly if two of the three questions are answered satisfactorily.

CHILDREN OF TEN YEARS.

I. Arranges five weights.-An excellent test which presupposes no schooling or acquired knowledge, and expresses intelligence in its most natural form; but it is a special intelligence, a sensorial intelligence, not at all verbal; and some children who use words easily fail to arrange the weights.

For this test we use five little pasteboard boxes, of identical size and color and indistinguishable one from the other by the eye alone. These are loaded, the filling being wrapped in cotton, and weigh respectivly $3,6,9,12$ and 15 grams. Each experimenter can construct his own. All that is required is a letter-scale and five small match boxes, the weights of which are varied by removing matches or adding sous; a set of boxes weighing $6,9,12,15$ and 18 grams can easily be made in this way, and may be substituted for our series.

The five boxes are placed in a pile before the subject. We say to him: "The boxes which you see here do not all weigh the same. Some of them are heavy and some are light. Place the heaviest one here, and at its side the one which is a little less heavy, then the one a little less heavy, 
then the one still a little less, and finally the lightest of all." While giving these directions we point to the place on the table where each box should be placed. This form of expression is not elegant, but we know that it is easily understood. Three trials are allowed, and after each the boxes are mixed, and the subject asked to begin again. The weights of the boxes may be written on the faces of the boxes which rest upon the table; it is easy to see whether the subject distinguishes the difference in the weights or not. To pass the test it is necessary that a child succeeds in two of three trials. Many children do not understand the explanation and remain motionless; so much the worse for them. Others place the boxes in any order without lifting them; and from the little attention that they give them, it is easy to see that they make no comparison. Others understand that the heaviest box must be placed first; and they distinguish between the weights of the others most accurately, but they are incapable of arranging the other boxes in the order of their decreasing weight; this idea of decreasing weight is unintelligible to them. They do not lack in sensibility to weight, but in the ability to arrange. Others finally grasp the idea of the decreasing order, and they come a little nearer to applying it; they arrange such series as $15,12,9,3,6$, where a single box is misplaced; they can do better, they fail from lack of attention and care. This is not a grave error. Nevertheless, we exact two absolutely correct arrangements. The time should not exceed three minutes.

We have already said that this test is one of those which best detect intelligence without culture, as it is absolutely independent of all instruction. We also remarked that the kind of intelligence indicated by it is of a very special nature. There are some children, very intelligent otherwise, who fail to arrange these boxes, while others do so accurately and with facility.

II. Copies drawings from memory.-The cilild is asked to draw from memory two drawings (Fig. 8, Appendix) after 
being allowed to look at them for ten seconds. The attention of the subject is prepared in advance; he is told that he will be asked to reproduce the drawings from memory, and that he will have but 10 seconds to look at them, and that 10 seconds is but a short time. It is difficult to estimate the exactitude of the reproduction without taking a number of measurements, which for our purpose would be unnecessarily troublesome. We have adopted the following rule, which is in practice quite convenient: The test is considered passed when one of the designs is reproduced exactly, and half of the other is correctly drawn; the section of the prism is always presented at the left; the subject's attention is usually attracted first by this picture, and it is doubtless for this reason that it is usually reproduced more correctly than the other one.

III. Criticises absurd phrases.-This is not the test of which we first thought. Our aim was to test the judgment of the child. For this purpose we employed a method used by some foreign alienists; we made absurd statements in order to see whether the child would assent to them. Here are some examples of absurd phrases which we used at first: "Why is there often a yellow dog when two men quarrel in the street?" "Why is a master often decorated when he plays billiards?" German alienists put questions of this kind to the insane: "Is the snow red or black?" We have found by experience that if children of very limited intelligence accept these absurdities, and try to find an answer for our strange question, other children, very intelligent ones, are also taken in by the trick. We have concluded that the acceptance of an absurd statement by a child does not depend entirely upon feebleness of judgment; it depends largely upon timidity, deference, confidence and automatism. We remember having dictated our absurd phrases, together with others which were not absurd, to a class of backward children at the Salpêtrière. Of course imbeciles and defectives were not lacking among them; but there were about fifteen children who could answer in writing. They formed a crowd, and the crowd is not timid 
nor deferential. Every time that we pronounced one of our "Why" absurdities, it was saluted by an explosion of ironic laughter, which came from all the pupils. The defectives comprehended the absurdity of our questions, and not being held back by reserve, they expressed their feelings noisily. All these reasons decided us to change the form of the test. Instead of asking the child to discover whether there is an absurdity or not, we tell him plainly that there is one, and that we want him to discover it and point it out to us; with this method no feeling of reserve, timidity or deference paralyzes the judgment of the child, if he is endowed with it.

The only difficulty about the test is to grasp the meaning of the child when he expresses himself badly by obscure phrases. Often the child has the feeling that our statement is absurd, but he cannot give the reasons for this feeling, cannot express himself in words. To feel is one thing, to explain the feeling another. It often happens that a child simply repeats the phrase, or the part of it containing the absurdity, without further commentary than his insistence on that part of the phrase, and his air of disapprobation. All this gives opportunity for much interesting analysis on the processes of comprehension and explanation. We will return to this elsewhere.

In making the test we begin with the following explanation: "I am going to read you some sentences, each of which contains something foolish. Listen attentively, and tell me each time what it is that is foolish." Then each sentence is read slowly, very slowly, in an impressive tone, and immediately afterward, in a changed tone, the child is asked: "What is foolish in that?" This test generally proves interesting on account of its novelty.

1.-An unfortunate bicycle rider fell on his head and was killed instantly; he was taken to a hospital and they fear he will not recover. Correct responses: As he is dead it is certain that he cannot recover. - If he is dead he cannot recover.-Seeing that he is dead, he cannot be cured.-You say that he is 
dead, then that he is taken to a hospital, and that they fear he will not recover! Incorrect responses: It is foolish to go bicycling.-It is foolish, to recover.-Hospital-There is nothing foolish in that.

2.-I have three brothers-Paul, Emest and myself. Correct responses: You have but two brothers. $-Y$ Yu are not your swn brother. - If you have three brothers you must have three brothers, you must not count yourself. You should say, I have two brothers. Incorrect responses: The foolishness is that you say myself.-You should say your name.-That which is foolish is Earnest.-The foolishness there is you.-There is nothing foolish.

3.-The body of an unfortunate young girl, cut into eighteen pieces, was found yesterday on the fortifications. It is thought that she killed herself. Correct responses: She could not cut herself into eighteen pieces.-If she cut off her arm she could not cut up the rest. Incorrect responses: It was foolish to kill herself.-The eighteen pieces are the foolish thing.-One cannot tell whether she killed herself.-There is nothing foolish.It is that it is not true.-She had no quarrel with herself that she should cut herself $u p$.

4.- There was a railroad accident yesterday, but it was not a bad one; the number of dead is only 48. Correct responses: It is bad if there are 48 dead; it is very bad.-It is not bad and the number of dead are 48! Incorrect responses: 48 dead.There is nothing foolish.-It is that there were no deaths. One should say many dead bodies.

5.-Someone said: "If I should ever grow desperate and kill myself, I will not choose Friday, because Friday is an unlucky day and will bring me unhappiness. Correct responses: If he kills himself, it makes mo difference whether it be Friday or any other day.-It makes no difference if he is dead.-If he killed himself on Friday it could not bring him bad luck.-He might as well kill himself on Friday as on Saturday; that is of no importance. Incorrect responses: Friday is just like any 
other day, it does not bring bad luck.-Friday is no worse than any other day.-The foolishness is killing himself.-The foolishness is the bad luck.-It is Friday.-There is nothing foolish. -One should not be superstitious.-Because one knows nothing about it.

Five sentences are enough to test the critical faculty. To pass the test a child must make at least three satisfactory responses. The test requires about 2 minutes. It is one of those which reveals very well the intelligence of a child.

IV. Understands difficult questions.-These questions are similar to the preceding ones, but more subtle, and present in addition some difficulties of vocabulary.

1.-What would you do if you were delayed in going to school? Correct responses: I would have to hurry.-I would have to run, etc. A misunderstanding of the question is shown in many of the incorrect replies. The subjects often answer as if they had understood; what will happen? They say: $B e$ punished.-Be put in the corner.-The teacher would slap me. Some even think of the future, and how they can best avoid a repetition of the tardiness: I would not do it again.I would leave earlier. Another misunderstanding is more subtle. The question which we ask implicitly signifies this: You are retarded; how make this retardation as little as possible? This is clearly the thought, but it is possible to miss it, and some have understood that they were asked how they would adapt themselves to the circumstances if they were actually too late. I would have to ring the bell (the door of the school is closed and the late pupils ring). I would bring an excuse from my parents. We consider, by convention, only one response correct; the first one: hurry.

2.-What would you do before taking part in an important affair? Correct responses: Think over the affair.-Reflect.Ask advice. Incorrect responses are not very intelligible. The subject usually has not understood the expression, "taking part." I should take care of the sick. -I should consult the doctor.-I should go away. 
3.-Why is a bad action done when one is angry more excusable than the same action done when one is not angry? Correct responses: Because an act done in anger is not intentional.-An angry person is not responsible.-An angry person does not realize what he does. The incorrect answers result either from a total failure to comprehend the question, or from the fact that the child's attention is arrested by the word anger, which suggests to him disapproval of that state. When one is angry one will not listen. He should not allow himself to get angry. This question is the most difficult of all, and often the child understands without being able to express his thought. The expression is not important if the experimenter is able to assure himself that the child has the thought that anger constitutes an excuse.

4.-What would you do if you were asked your opinion of someone whom you did not know well? Correct responses: I could not give any.-I could not speak without knowing.-I would have to be silent for fear of giving incorrect information. The incorrect responses are usually unintelligible. I should hav'e to ask. I should have to answer. Say to him, Be wise. Say that I did not know his name.

5.-Why should one judge a person by his acts rather than by his words? Correct responses: Because words lie and acts speak the truth. Because one is more sure of acts than of words. Incorrect answers, unintelligible: It is unnecessary to lie. Because one does not know. With the two preceding tests, one is often met by the silence of the child, and the difficulty is to know what this silence covers; it may be that the child can think of no reply or that he has thought of an incorrect one which fails to satisfy him, or even that he has thought of a good answer which does not satisfy his judgment. The experimenter is often quite puzzled. Consideration of the whole group of a child's answers assists much in the judgment of each. The examiner should have the patience to allow the child at least 20 seconds for reflection on each question. Two incorrect responses in five are allowed. 
At seven and eight years the majority of the questions in this second series are never answered correctly; at ten years scarcely half of the children succeed. This test is then for the transition period between ten and eleven years.

In a general way this is the best test of intelligence, as commonly understood, in the whole series. Sometimes, after an examination one hesitates on a diagnosis. The child has failed in one or two tests, but this does not seem convincing. Failure to give the day and date and the months of the year are excusable errors, which may be caused by distraction or by lack of education. But the questions for comprehension dissipate all doubts. We recall several instances when teachers brought us children, desiring to know whether or not they were abnormal. Occasionally, in this way they set a trap for us, but we did not object; it was fair play. Our questions for comprehension decided us every time. We remember one child who was very slow in answering, as though dull; his face was expressionless and unprepossessing; he knew neither the day nor date, nor what day comes after Sunday, and he was $10 \mathrm{r} / 2$ years old; his reading was still syllabic. But when we asked question 5: Why do we judge a person by his acts rather than by his words? he gave the following answer: Because words are not very sure and acts are more sure. This was enough-our opinion was formed; that child was not so dull as he seemed.

$\mathrm{V}$. Uses three given words in two sentences.-This is the first time that we have asked for an invention. This one is verbal. It presupposes that the child talks, writes, and understands the meaning of the expression "a sentence." Three words are written on a piece of paper-Paris, Fortune, Stream. They are read to the child several times, then he is told: "You make a sentence and use in it these three words." $\mathrm{He}$ is then given a pencil. Some declare that they do not understand; often it is the expression "make a sentence" which confuses them. No other explanation should be given them, but the first instruction may be repeated. Others understand, but 
either think of no sentence whatever, or one that fails to satisfy them. As these last may be purists, it is necessary to insist that they write some sentence. The sentences written may be divided into three principal groups:

1. Three distinct ideas are given.-Examples: Paris is a city, someone has a fortune, the stream flows.-Paris is a small city, a fortune is many cents, a stream is a little river running through a gutter at the side of the pavement.

2. Two ideas are given.-Examples: In Paris there are some streams and men who have large fortunes.-Paris possesses streams and a fortune.

3. Only one idea is given.-Example: The Seine is a stream which brings a fortune to Paris.-In a stream at Paris I found a fortune.-A drunken man without fortune has been found in a stream at Paris.

Another type of sentence, somewhat similar to this unified form, is that in which several phrases are used, but well co-ordinated. I live in Paris; a gutter carrying a stream of water to the sewer runs through the street on which I live. I know a man living a few doors from my father who has a large fortune.-In my youth I was in Paris; for a month I drifted with the stream, then a man took pity on me, he adopted me, and at his death I inherited his fortune.

We find in these sentences a means of distinguishing several stages of mental development. We retain but two, the last two. The three words in two sentences and the three words in a single sentence. The first of these tests, the three words in two phrases, is never passed at seven years, an age when a child does not write sufficiently well to succeed. At eight years, none, or almost none, succeed. At nine years, one-third of the children, and at ten years, one-half succeed. We allow one minute to write the sentence. If at the expiration of one minute the sentence is not written, or at least three-quarters written, the child fails. Note that this is one of the rare tests the results of which may be influenced by 
information carried from child to child. We have had such experience.

A second remark: We have already said, apropos of pictures, that it is necessary to make a distinction between the level of intelligence and the judgment, and have cited the example of an adult who had reached an advanced mental level, being able to interpret pictures, who nevertheless gave expression to ridiculous ideas in the midst of his interpretations. This distinction between the judgment and the intellectual level appears subtle, but it is not. We again find it in this test. There are children who compose a single sentence containing the three given words, but the sentence is devoid of sense and they fail to see it. Examples: Paris is a city of fortune by the stream.-At Paris, where there are streams, they make fortunes.-Paris is a great fortune, which has a large stream.

These sentences are correctly constructed, and prove their authors to be of the mental age of twelve years, but they at the same time prove them to be very weak in judgment. Ulterior researches will doubtless show how much importance should be attached to these facts.

\section{CHILDREN OF TWELVE YEARS.}

I. Resists suggestion (length of lines.)-This test belongs to the twelfth year. A little white paper book of 6 pages is made. On the first page two lines are drawn with ink $a$ and $b$; the first, that is, the one on the left, is four centimeters long, and the second five centimeters; they are placed in line with each other and one centimeter apart; on the second page two similar lines are drawn, the first five centimeters, the second six; on the third page the first line is six centimeters and the second seven. On each of the three following pages two lines are drawn in the same position, but all are of the same length, seven centimeters. We have, then, if we designate the lines by the letters of the alphabet, the following order: 


$$
\begin{aligned}
& a<b \\
& c<d \\
& e<j \\
& g=h \\
& i=k \\
& l=m
\end{aligned}
$$

In showing the first three pairs of lines, the experimenter says to the child: "Which is the longer of these two lines?" When the three last pairs are reached, the form of the question is slightly changed, and he limits himself to the words, "And these?" The child succeeds in the test if he judges two of the last three pairs of lines to be equal. Experience proves that very young children, even those of seven years, are capable of distinguishing the difference between the lines $a$ and $b, c$ and $d, e$ and $j$. When the equal lines are reached, the child is played upon by two influences; first is the influence of training. Until now, during three trials he has seen that the line to the right was the longer; it is then natural to suppose that this will continue; it is a supposition, a generalization, in such cases where the operation is a conscious and reflective one; but we think that most often there is no conscious process, but an unreflective tendency, a budding automatism, a habit. It is rather a sketch of a habit, a habit in the making, certainly not very strong or resistant; but, nevertheless, it exists, and can determine alone the kind of response, if no cause for a contrary response comes up to oppose and frustrate it. The second influence is that of reflection, founded on the perception of the lines; a single glance suffices to show that that on the right has ceased to be longer than that on the left. And if the child reflects, he will resist his automatism and no more say that the line on the right is the longer. He will, on the contrary, declare them to be equal. Thus analyzed theoretically, the test appears to be a revelation of the suggestibility of the child; the most suggestible are those who are led by the automatism in judging the 
three pairs of lines; the least suggestible are those who declare equal the three pairs of lines; and finally we count, following our accustomed rule, two correct responses in three sufficient for success.

As the term suggestibility has several meanings, it is important to add that it signifies here not that suggestibility due to defect of character or judgment, but that resulting from heedlessness, from lack of attention. It is because the child depends upon habit and does not pay attention to the real length of the new lines which are shown him, that he falls into the trap. But we are not sure that this analysis of this particular form of suggestibility is entirely correct. Suggestibility rarely depends upon intelligence alone; character and feeling have also an influence. The child who has formed the habit, under his master's eye, of answering that the longest line is the one to the right is emotionally excited to persist in this answer, to the right; he is actually forced to do so; sometimes he perceives that he has erred, blushes and is ashamed and ill at ease, but he does not correct himself, he persists in his error. There is some emotional trouble-a strange one, not yet well analyzed.

II. Uses three given words in one sentence.-This test is explained above. All children succeed at twelve years and scarcely a third at ten.

III. Says more than sixty words in three minutes.-The child is told to name in three minutes as many words as he possibly can. Such words as table, beard, shirt, carriage, etc. His ambition is aroused by telling him that some children have named more than 200 words, which is perfectly true. This test is very interesting, for it is fertile in suggestions; besides the number of words, one can note their relations; some subjects give only detached words, each of which requires an effort to recall. Others give a series of words, the furnishings of a school, various articles of clothing, geological terms, etc. Some use only names of common objects; others 
cite abstract qualities or rather far fetched words. All this gives an idea of the mentality of the subject. The use of series of words and of abstract terms indicates a certain amount of intelligence and culture. But in our test we take account only of the number of words. At least 200 words may be given without hurry in three minutes' time, provided no effort is required to think of them. But such effort is necessary, and everyone has not the same power of recall. Little children exhaust an idea in naming it. They say, for example, hat, then pass on to another object without noticing that hats differ in color, in form, have various parts, different uses and accessories, and that in enumerating all these they could find a large number of words. Their lack of skill in the use of language and in the analysis of ideas is very striking. Some children of ten years spend as much as 30 seconds trying in vain to think of a word. By this test we are able to estimate, according to observations which we have made elsewhere, both the intellectual activity of an individual and his verbal type. Those who have many words at command, those who think in words, those who habitually think of abstract subjects, or those who are fond of puns appear to have the advantage over others. Sixty words is the minimum requirement. Children of twelve years succeed, sometimes giving as many as 150 or 200 words; one of our subjects gave 218 .

IV. Defines abstract terms.-Definitions are required for three abstract terms-charity, justice and kindness. The formula used is very simple: What is

Charity.-A good definition should contain two ideas: that of unfortunate people and that of kindness shown them.-Good responses: It is the act of aiding people who are in trouble.It is giving money to the old who are unable to work.-It is to give alms. - Charity is to have pity for the poor people one meets, and if one has some money, to give them some. Bad responses: It is to be good.-It is to be charitable.-It is to beg.-It is a person who is good.-It is a poor person.-It is to ask pardon. 
Justice.-A good definition contains the idea of law, that is to say, of rule, of protection accorded to people and their interests, or the idea of people being treated according to their merits. Good answers: Justice is an act which consists in sentencing persons who are guilty and in dismissing those who are innocent.-It is a law which rules.-Justice is to punish the zuicked even though they be rich. Incorrect responses: Justice is that which judges.-Justice is a judgment.-It is where people are judged.-It is to cut the throat.-It is agents.

Kindness.-A good definition should express the idea of affection, of tenderness, or simple acts of kindness where no inequality of condition exists between those who give and those who receive. Good definitions: Kindness is to be polite to others.-Kindness is to wait when a person cannot pay, and not to beat other people.-It is to return good for covil.-Kindness is to share with others. Incorrect responses: Kindness is to be kind.-It is to do something good.-Kinduess is to be very zell dressed.-It is to lift one's hat.-Kindness is diligence.Kindness is to be presumptuous.

Two correct definitions are required. This test is sometimes difficult to interpret. At eight and nine years some children give good definitions, but this is quite rare. At ten years one-third succeed, at twelve years the majority.

$V$. Derives the sense of a sentence the words of which are mixed.-This test is suggested by the tests of Ebbinghaus which require the subject to supply missing words in sentences. We use the three following groups of words which we present to the child, saying: "Put those words in their proper order and find the sentence which they make."

1. For - an - the - at - hour - early - we - country -started.

2. To-asked-exercise-my-I-teacher-correct-my.

3. A-defends-dog-good-his-master-bravely.

Solutions: (1) We started at an early hour for the coun- 
try, or, At an early hour we started for the country. Incorrect responses: We started country

(2) I asked my teacher to correct my exercise.

(3) A good dog defends his master bravely. Another arrangement not so good is: $A$ dog defends his good master bravely. Incorrect arrangements: A master defends his good dog bravely.-A dog defends his master bravely good.

It is a puzzle which interests many children. There is much individual difference in the rapidity with which the solution is formed. Some only take 5 seconds, others 20 and sometimes even 50 seconds. The time limit is one minute for each sentence. Two correct solutions are required.

Some children, failing to comprehend the instructions, supply words or compose sentences having no connection with the given words. For example, one gave the following sentences: The dog runs. $-I$ defend my country.-I bought some candy.

\section{CHILDREN OF FIFTEEN YEARS.}

I. Repeats seven digits.-This test is made in the same manner as that calling for the repetition of five digits. The child is told in advance that he will have seven numbers to repeat. One success in three trials suffices.

II. Gives three rhymes.-We begin by asking the subject whether he knows the meaning of the word rhyme. Whether he knows it or not (and often he thinks that he knows it when in reality he does not) we give him the following explanation: "Two words which rhyme are two words which end with the same sound. Thus, pumpkin, napkin-pumpkin! napkin! They both end in kin. In the same way mutton rhymes with button; they both end in ton. Do you understand? I am going to say a word and then you will try to think of all the other words which rhyme with it. It is the word obey. Find all the words which rhyme with obey." One minute is allowed for reflection and the child is required to find three 
rhymes in this time. He can be urged but not assisted. He usually begins by giving disobey. Sometimes a series of words are given which do not rhyme. Sometimes words are coined with the required ending or even with some other ending. Finally some children who have understood nothing repeat pumpkin, napkin, while others, differently oriented say: To obey, I obey, I disobey, or punishment, naughtiness. Some even cite various examples of disobedience: To take things belonging to the other children, to kick, etc. This test is one of the easiest to estimate.

III. Repeats a sentence of 26 syllables.-We have composed a series of 22 sentences regularly increasing in length, from 2 to 44 syllables, and each formed of words very easy to understand. By the use of these we can easily measure an individual's ability for verbal repetition. When the sentences are presented to a subject in the order of their length the following facts are always noticed: Certain sentences are exactly reproduced, then, as their length is increased, insignificant changes are made in the reproduced phrases; the place of a word is changed, a nonessential word is onitted or replaced by a synonym. These slight alterations occur in a zone corresponding to an increase of 6 to 10 syllables. Finally grave omissions occur; an essential part of the sentence is forgotten or modified. We think it best to allow no error.

We will remark in passing that the memory for verbal repetition does not increase much from the sixth to the tenth year in spite of the immense intellectual difference which separates these two ages.

Thus a series of children six years of age, taken from the school Maternelle, gave the following series of maxima for repetition: $22-18-20-18-20-24$, A series of children of nine and ten years gave: $16-22-22-22-22-22-22$. One would expect a much greater difference. Decidedly the power of memory does not increase greatly with age. 
At 15 years we require the correct repetition of a sentence of 26 syllables. These are the sentences which we use:

24 syllables: My little children, you must work very hard for your living; you must go to school every morning.

26 syllables: The other day I saw on the street a pretty yellow dog. Little Maurice has stained his nice new apron.

28 syllables: Ernest is frequently punished for his bad conduct. I bought at the store a pretty doll for my little sister.

30 syllables: There was a severe storm last night with much lightning. My comrade caught cold and he now has a high fever and coughs a great deal.

32 syllables: The car is less expensive than the omnibus, it costs but two cents. It is strange to see women acting as coachmen in Paris.

IV. Interprets a picture.-See above.

V. Solves a problem from several facts.-Another problem, but one which requires good sense rather than insight. We have drawn up two situations each of which presents a problem. Here they are:

1. A woman walking in the forest of Fontainebleau stopped suddenly dreadfully frightened, hurried to the nearest policeman and told him that she had just seen hanging to the limb of a tree (after a pause) what?

2. My neighbor has just received some singular visitors. He received one after the other a doctor, a lawyer and a priest. What is going on at my neighbor's?

Both of these questions pique the curiosity of the subjects. To the first some have replied: A bird, a snail, a bird nesi hunter, a robber, an apache, an assassin, a tree trunk, a branch, a bunch of grass.

The only correct response, implied by the context is: $A$ person who has been hanged. 
For the second question the correct response is: He is very ill, he is dying.-Someone is very ill there, dead. Incorrect responses: I do not know. An erroneous answer often consists in a repetition of the question. It happens that he has received a doctor and a priest.

A correct response to each question is required.

\section{ADULTS.*}

I. Solves the paper cutting test.-A square sheet of paper folded along both diameters is given to the subject; in the middle of the edge which presents but a single fold, a small triangle $(1 \mathrm{~cm}$. in height and having for its base the paper's edge) is drawn. We say to the subject: "Here is a sheet of paper which has been folded in four; suppose that here (pointing to the triangle) I cut away the little triangle of paper which is marked out. Now, if I should unfold the paper, what would I see? Draw the paper, showing how and where it would be cut" (Fig. 10, Appendix). The subject is not allowed to touch the paper in any manner, and is forbidden also to fold another piece of paper. The attempt to represent the result of cutting the folded paper must be guided by the imagination alone.

The test is difficult. Most subjects simplify the solution greatly. They think that only one hole is cut, a square or a lozenge, sometimes a 5 pointed star, and that its position is the center of the paper. This position is suggested by the position of the triangle in the middle of the edge. Some draw two lozenges side by side. To be correct, two lozenges must

*NOTE.-It is not necessary to take the expression "adult" literally and to suppose that the tests placed under this rubric indicate the intellectual level of an adult. Adults have very different intellectual levels dependent upon the social class to which they belong; there does not exist a single adult level but several. The tests given here simply indicate a level which is clearly higher than that of 15 years. 
be drawn in line with each other and each placed in the middle of one-half of the paper. When a child succeeds in this test in his first attempt, it is always necessary to ask him whether he was already familiar with it.

II. Reconstructs a triangle.-A visiting card has been cut in two pieces along the diagonal (Fig. 11, Appendix). The pieces are placed on a sheet of paper in their original position. The subject is directed: "Look well at the lower piece. Suppose that I turn it around and place this edge (tracing the edge $a-c$ with the finger) on this edge ( $a-b$ of the upper piece). Suppose further that the point $c$ is placed just on the point $b$. Now, I take away the piece; in your imagination, place it as I have described and draw its outline in this position. Commence by following the outline of the upper piece." The test is very difficult. It is required that the subject draw a right angle at $b$, and that the edge $a c$ be shorter than the edge $a b$. Often only one of these conditions is fulfilled.

III. Gives difference in meaning of abstract terms."What is the difference between laziness and idleness?-Between event (événement) and advent (avènement).-Between an evolution and a revolution?" These are the questions that are asked. Correct answers to two suffice. In stating the difference between idleness and laziness it is necessary to point out that the former results from external circumstances, while the latter is an individual characteristic. For the distinction between event and advent it is hardly necessary to mention that an event (événement) is something that takes place, while an advent (avènement) is a king's ascension to the throne.* An evolution is a slow progressive change; a revolution is a sudden change; some persons take the word

*TRANSLATOR'S NOTE.-As it seems impossible to retain both meaning and similarity of sound of this pair of words, we have translated avènement, advent, and of course accept a general meaning instead of the particular one noted in the text. 
evolution in the sense of the maneuvers of a troop and revolution in the sense of a grave popular insurrection; in this case the distinction is not so good, as the two words are different without being opposites, and it should be understood that we are asking for oppositions and not simple differences. However, these responses are considered valid.

IV. Solves the question concerning the president.Question: "There are three principal differences between a king and a president of the republic. What are they?" They are the following: Royalty is hereditary, it lasts during the life of the monarch, and it confers very great powers; a president of the republic is elected, his term of office is limited, and his powers are not so great as are those of a king.

V. Summarizes an observation made by Hervieu.-The following paragraph is read slowly and impressively: We call it the thought of Hervieu; the thought only is borrowed; he wrote it in three lines, but his arrangement was not adapted to our needs; we have amplified it to prevent its being retained absolutely by the memory, as it would be in its original brief form.

Many opinions have been given on the value of life. Some call it good, others call it bad. It would be more just to say: that it is mediocre, for on the one hand our happiness is mever so great as we would have it, and an the other hand our misfortunes are never so great as others would have them. It is this mediocrity of life which makes it just, or rather which prevents it from being radically unjust.

Before beginning the reading we tell the subject to listen with care because he will be asked at the close of the reading to repeat the selection. In this manner the test is placed in the field of memory; and those who do not succeed in comprehending the rather subtle thought of Hervieu, will be spared the embarrassment of feeling that they have betrayed a lack of comprehension; the failure will be attributed to 
faults of memory and attention, and this is infinitely less painful. The central thought, which it is necessary to reproduce, is the following: "Life is neither good nor bad, but mediocre, for it is inferior to that which we desire, and superior to that which others desire for us." The terms used matter little; the essential thing is that the thought be well understood; and this will be the less doubtful, the less the subject tries to repeat the text verbatim. 


\section{PART II.}

Description of the conditions necessary for a satisfactory examination.-In the first place use an isolated, quiet room. Be alone with the child as much as possible and have a secretary to take the child's replies verbatim. A child of thirteen or fourteen may be used for this purpose, if a very intelligent one is chosen and some supervision given. Meet the child pleasantly, do not stare at him when questioning him; if he seems timid, constantly reassure him, not only by a pleasant manner, but by using one of the tests which seems most like a game (pictures or making change). Encourage constantly in a kind way throughout the examination; show satisfaction with the answers whatever they are. Never criticise, and do not lose time by making a lesson of it. There is a time for all things. The object now is to judge of the mental plane of the child, not to instruct it. Above all, never aid the child by a supplemental explanation which may put him on the right track. One is often tempted to do this, and it is wrong; one feels uneasy and fears the child has not understood. Vain scruple, because the test is the sort that should be understood. Hold closely, then, to the formula for each test without addition or retraction. Encouragement should be given by the tone of voice, or by words wholly devoid of meaning which serve only to stimulate: "Go on! Quickly now! Hurry up! Good! Very good! Perfect! Marvelous! etc." If it is necessary to have a visitor, insist upon his absolute silence. How difficult to secure! Every teacher wishes to interfere in the examination, to give a supplementary explanation, especially if the child belongs to her class. Have the courage to enforce silence.

Commence with each subject by using the tests designed for his age. If too difficult tests are tried at first he is dis- 
couraged. If on the contrary they are too easy, he grows disdainful, wonders whether he is being made fun of and makes no effort. We have seen manifestations of this misplaced pride.

In reference to the experimenter, himself, some conditions are necessary. He must not allow himself to be prejudiced by information obtained from other sources. He should banish from his mind all that he has been told concerning the child and consider him as an $\mathrm{X}$, which he must solve with the means in his power. He should be firmly convinced that in using the method one must necessarily gain a profound knowledge of the child, and so entirely ignore all other information. But this confidence in one's self often fluctuates. At first all appears easy; it is the epoch of illusions. After a few trials, even the least critical see errors everywhere and are discouraged. But if one works on, long and patiently, confidence returns little by little; it is not now the optimism of the beginner, it is a reasonable, reflective confidence. One is conscious both of his powers and of his limitations.

This initiative period lasts for at least 5 or 6 séances of two hours each; and represents examinations of twenty children. All experimenters intending to use the method should submit to such a preparation.

The tests should be prepared in advance; the little material required should be close at hand; all the required coins should be kept in a special purse. Two records should be kept; the first recording the numerical results of the tests, and the second, a note book, recording the responses in detail.

The first record is a large sheet of paper ruled in squares on which are written in a column at the left, the names of the tests, grouped according to age. Following these names as many parallel columns are drawn as there are children to be examined, each being headed by the name of the child. After a child has been examined, the result for each test is recorded 
in the column reserved for that child, and opposite the test names; the results are expressed by the following symbols: The sign + indicates that the test is passed; the sign - indicates failure; the sign 0 indicates a silence; the sign ? indicates that the result is doubtful; if a doubtful result is nearer failure than success the sign -? is used; if it is nearer success the sign + ? When the result is excellent we use $+!$ and when it is altogether bad ! We advise that the sign be recorded immediately after the test is completed, not after the examination upon the reading of the notes. It is easy to understand why we so advise. In recording a symbol we do not register automatically what takes place, but we record a judgment, and this judgment stands a greater chance of being correct when the occurrence is more recent. No matter how detailed the notes, they reproduce but very incompletely the actual experience; an enormous amount of detail is omitted, as a matter of course, to be supplied by the memory of the experimenter; it would be wrong to trust entirely to the notes.

Having marked the results of the tests by signs, more extended notes are recorded in the note book. This should contain the full name of the child, his age, date of birth, the date and place of examination, the quality of the assistants and any exceptional circumstances influencing the examination. Often this information is not recorded; later, on referring to the record it cannot be supplied. We advise also keeping a record of the school standing of the child, the number of pupils in his class, the attitude of the child during the examination (natural, heedless, timid, dull, undisciplined, etc.) and finally the social scale of the parents (want, poverty, mediocrity, ease, riches.) If, by chance, some important fact in the history of the child is discovered, record it also. If a little boy of nine coming from a country district has never attended school, this must be noted.

The notes relative to each test which should be recorded in this book, vary; experience is the best teacher of what is 
useful to preserve. It is necessary to bear in mind that the symbol alone is altogether insufficient, and that we should have sufficient data to enable another experimenter to judge of them on his own account. Thus, in the responses to the questions involving the reasoning powers, the manner in which the child explains or criticises the absurdities of certain phrases must be given at length; in using the test requiring the repetition of figures it is well to have model series and not to vary them; then the figures the child gives may be recorded; this precaution will guard against the possible loss of interesting facts. Example: The experimenter recites: 1-3-9-2-7. The child believing himself repeating, says: $1-3-4-5-6$. The error is very grave, graver than had he said: $1-3-8-5-0$; for in the first repetition he has followed the natural order of numbers, and by so doing has implicity admitted the absurdity that he has been asked to repeat numbers in their natural order. A little commentary helps to fix the result in memory. The definitions of words and objects and the resumé of the thought of Hervieu should be written in detail. In the test calling for 60 words it is sometimes difficult to write all the words given by the child; interesting indications can, however, always be secured; for example, each word may be represented by a vertical line, and a new group be started every half minute (the total test lasts three minutes); thus a record is secured of the number of words written in the first half minute, the number in the second, the number in the third, etc.; this shows whether the subject has increased or decreased in speed as the experiment progressed, and this in turn gives some indication of his ability to work; I am also in the habit of dotting the lines which correspond to the names of objects mentioned, and of underlining those which stand for an unusual word, one not in common use. We advise that the rhymes given be recorded and also the sentence containing the three given words. By exacting all these notes from collaborators it is possible to judge with what care the experiments have been made. A record of the intelligence of a child, presented without other 
data than some symbols, certainly seems subject to doubt; it can not be tolerated; it would encourage negligence and even fraud.

Utilization of Notes.-We have recorded a series of signs in vertical columns; these signs succeed each other irregularly; here there is a - , there $a+$. How shall we interpret them? It is at once evident, that no matter how the tests are arranged it is impossible to find an order in which one test will mark the limit of achievement, all tests preceding it being passed successfully and all those following being too difficult. Such an order can easly be arranged for one individual, but it would not prove satisfactory for a second and a third. Let us examine the effect of the order which we have adopted, as shown in an examination of 10 children, nine years of age. In the tests for the ninth year which amount to 50 (as there are 5 tests and 10 pupils) these ten children failed in 6 and succeeded in 44 . In the tests for the tenth year, they failed in 14 and succeeded in 36 . We do not find a limiting test, which foils all, and which only foils children of this age or younger. That would be a useful criterion, but we have not discovered it and do not believe that it exists. The reality is less simple. The experiment shows us the following fact: The nine-year-old children succeederl in all the very simple tests, they succeeded in none of the very difficult ones; in the tests of moderate difficulty, some children succeeded with certain ones, and some children with others. This varied with each child. This is the fact which we are obliged to consider. Each child has its own individuality; one succeeds well with test $A$ and fails with test $B$; another of the same age, fails with test $A$ and succeeds with test $B$. How shall we deal with these individual differences in our experimental results? We have no exact knowledge concerning them; it is probable that the mental faculties stimulated by the tests differ and are of an unequal development in different children. If a child has a better memory than his companions, it is natural for him to be more successful in a test of simple repetition. Another who has already a capable 
hand will arrange the weights more successfully. Another reason is that all of our tests presuppose an effort of attention and the attention varies during a period of concentration, especially with young people; now it is intense; one minute later it is relaxed. Suppose that the subject has a moment of distraction, of embarrassment, of ennui during a test, it may cause complete failure. One cannot doubt the justice of this last reason. We are so convinced on this point that we think it chimerical and absurd to judge the intelligence of a child by one test alone.

The preceding considerations lead to the conclusion that the intellectual level of a child can be judged only by a group of tests. It is success in several distinct tests which abone is characteristic. Intelligence cannot be estimated as can the height. For height it suffices to have a table of mean heights for the various ages; given a child we measure it, and then turn to the table of means; it is very easy by a simple comparison to ascertain whether the child measures up to the standard height of children of his age, or whether he is retarded one year, two years, etc., or, on the contrary is advanced one year, two years, etc. There is very little artificiality about this method of estimation.

It is altogether otherwise when we estimate the intelligence. If one wishes to apply the same system of comparison between the intelligence of one child and the mean intelligence of children of different ages one is arrested by the difficulty which we have mentioned above; a child is retarded for certain tests of his age and advanced for others. We think, however, that this difficulty can be overcome; but it is on condition that we adopt some convention; and the said convention, be it the best possible, will always give to the proceeding an artificial character. If by chance another convention had been adopted sensibly different results would have been reached. We feel it necessary to insist on this fact, because later, for the sake of simplicity of statement, we will speak of a child of eight years having the intelligence of a child of seven or of nine years; these expressions if accepted arbitrarily may give place to illusions. It is necessary to re- 
member that the estimate of the amount of retardation or precocity of intelligence depends partially upon the conventional proceeding which we have adopted.

The rules which we apply are two. The first is as follows: A child has the intelligence of that age all the tests for which he succeeds in passing. Here is a child nine years of age who passes all the tests for the seventh year, he has then at least the intelligence of a child of seven. The second rule is as follows: After determining the age for which a child passes all the tests, a year is added to the intelligence age, if he has succeeded in passing five additional tests belonging to superior age groups, two years are added if he has passed ten such tests, three years if he has passed fifteen, and so on.

Thus a child passed the five tests for the eighth year; he has the intelligence of eight years; in addition he passed three tests for nine years and two tests for ten years; we add one year for the five tests, the record stands $8+1=9$, and the child has an intelligence of nine years. Another example: A child passed the 5 tests for 6 years; he has the intelligence of 6 years; he also passed 3 tests for 7 years, 3 for 8 years, 2 for 9 years, 2 for 10 years, and 1 for 11 years; this gives him eleven extra tests, and adds two years to his intelligence age, making it 8 years. A last example: A child passed all the tests for 4 years; he passed in addition 1 test for 5 years, 3 for 6 years, 2 for 7 years, 4 for 8 years, 3 for 9 years, and 2 for 10 years; he has passed then 15 additional tests which is equivalent to 3 years and he is accorded the mental age of 7 .

The result of this notation is that it qualifies a child as regular in intelligence if it has an intelligence age equal to its age; as advanced in intelligence if it has an intelligence 1 or 2 years greater than its age, and as retarded in intelligence if it has an intelligence 1 or 2 years inferior to its age. The symbols used to express the results are $=$ or $+1,+2,+3$, etc., or $-1,-2,-3$, etc.

We would add that a child should not be considered defective in intelligence no matter how little he knows unless 
his retardation of intelligence amounts to more than two years.

Remarks:-The researches which have enabled us to calculate our norms, were made in those primary schools of Paris which are situated in the poorer disticts. Experience has demonstrated that the children of persons in easy circumstances present in general a higher intellectual development than that expressed by our means. Thus, in a private school, frequented by the bourgeoisie, and where the classes consist of from 8 to 10 pupils, the pupils show a mean one and one-half years in advance of our normal means. It is important to add that our examinations have been made but once, and by a stranger, who, without intimidating the child, inspired him with a certain deference. Other results would be obtained if the examination were repeated several times or if it were conducted by a person too well known to the child to produce a deferential attitude, etc., briefly, if the very precise conditions which we have indicated, were ignored.

If a child is to be examined the second time, it is best to allow a period of at least 6 months to intervene between the examinations, and to guard against the coaching of the child by his companions.

A last word for those persons who desire to employ the method. Any one can use it for his own personal satisfaction or to obtain an approximate evaluation of a child's intelligence; but for the results of this method to have a scientific value, it is absolutely necessary that the individual who uses it should have served an apprenticeship in a laboratory of pedagogy or possess a thorough practical knowledge of psychological experimentation. 
APPENDIX 



\section{TESTS ARRANGED IN AGE AND DIAGNOSTIC GROUPS FOR CONVENIENCE IN CON- DUCTING EXAMINATIONS.}

\section{IDIOTS.}

\section{Mental Age 1 and 2 Years.*}

1. Move lighted match slowly before child's eyes. Full credit given if eyes follow light for briefest period.

2. Place a wooden block in child's hand. Credit given if block is grasped.

3. Show the wooden block without touching child with it and say: "This is for you, don't you want it to play with?" Credit given if child takes it.

4. Offer child a piece of wood and a piece of chocolate of the same size. Credit given if he eats the chocolate and does not attempt to eat the wood.

5. Show child a piece of chocolate, then wrap it in paper and present it to him telling him to eat it. Credit given if he removes the paper before eating.

6. Make simple movements, clapping the hands, sitting down, standing up, etc., and tell the child to do the same. Credit given if one intention is accomplished.

*These tests for children of 1 and 2 years of age are taken from the 1905 series, Methodes nouvelles pour le diagnostic du niveau intellectuel des anormeau, L'Année Psychologique 11, 1905, page 199. 


\section{IMBECILES.}

\section{Mental Age 3 Years.}

7. Show me your nose. Show me your eyes. Show me your mouth.

8. Listen well and repeat what I say: $4 ; 3-7 ; 6-4$; 5-8. Pronounce numbers slowly and distinctly with one-half second interval between, one pair at a time. Full credit given for one exact repetition.

9. Place Picture 1 before child and ask, "What is that?" or "What do you see there?" Follow this by Pictures 2 and 3 . (Figures 1,2,3.) Full credit given if some objects are enumerated.

10. "What is your name?" If first name only is given"And your other name?"

Surname required.

11. "Listen well and repeat what I say: I am cold and hungry." No errors of any kind allowed.

\section{Mental Age 4 Years.}

12. "Are you a little boy or a little girl?" If necessary"Are you a little girl?" "Are you a little boy?"

13. Show child a penknife, saying, "What is that? What is it called?" Then show penny, and finally key, asking same questions. Names of three objects required.

14. "Listen well and repeat what I say: 4-9-2;3$7-4 ; 5-8-1 . "$ Full credit given for one exact repetition.

15. "You see these two lines. Tell me which is the longer." (Fig. 12.)

\section{Mental Age 5 Years.}

16. Place two boxes weighing 3 and 12 grams, respectively, on the table before the child, leaving a space of 5 or 6 centimeters between them, and say, "You see these two boxes? Tell 
me which is the heavier." Repeat, using boxes weighing 6 and 15 grams, and repeat again, using first pair.

If there is still doubt about the child's ability to compare weights, repeat process.

17. Draw a square 3 to 4 centimeters in diameter with ink and ask the child to copy it, giving him pen and ink to do so. (Fig. 19.)

18. "Listen well and repeat what I say: My name is Charley. O! the naughty dog."

19. Place four pennies in a row before the child and say: "Do you see these pennies? Count them and tell me how many there are."

Child is required to point to each with finger; no error allowed.

20. Place an oblong card on the table before the child, and place also, nearer to the child, two triangular cards formed by cutting another card like the first one in two, along a diagonal. Place these two triangular cards in such position that their hypotheni form a right angle one with the other, then say to the child, "Put these two pieces together so that they will form one card like this" (indicating the oblong card). If the child turns over one triangular piece without noticing it, it is permissible to begin again.

\section{Mental Age 6 Years.}

21. "Is it morning now?" "Is it afternoon now?"

22. "What is a fork?" "What is a table?" "What is a chair?" "What is a horse?" "What is a mamma?"

If some use of three of the objects is mentioned the response is considered correct.

23. Draw a diamond figure with ink and ask the child to copy it, giving him pen and ink for the purpose. (Fig. 20.)

24. Place 13 pennies in a row on the table before the child and say: "Count these pennies for me, pointing to each one as you count it."

25.. Show pictures of faces (Fig. 6). Expose first the 
upper two alone, next the two middle ones, and last the lower ones, saying each time, "Which is the prettier of these two faces?" No error allowed.

\section{Mental Age 7 Years.}

26. "Show me your right hand." "Show me your left ear." No error allowed.

27. Show pictures as in Test 9, asking the same questions. Full credit given if two pictures are described.

28. "Take this key and put it on that chair, bring me that book lying on the table and open the door." Give these directions distinctly twice.

29. Place three two-cent and three one-cent stamps on the table before the child. Make sure that he knows the 2's from the 1's and then ask him to count how much they would all cost.

30. Have four pieces of colored paper, red, blue, yellow and green., Point to each asking, "What is this color?" (Fig. 21.) No error allowed.

\section{MORONS.}

\section{Mental Age 8 Years.}

31. (a) "Do you know what paper is:" "Do you know what cardboard is?" "Are they alike?" "In what way are they not alike?"

(b) "Have you ever seen a fly?" "Have you ever seen a butterfly ?" "Are they alike?" "In what way are they not alike?"

(c) "Do you know wood when you see it?" "Do you know glass when you see it:" "Are they alike?" "In what way are they not alike?" Two satisfactory answers required.

32. "I want you to count backward from 20 to 0 . Like this-20-19-18." This must be accomplished in 20 seconds. One crror allowed. 
33. The four pictures in Figure 7 are shown one at a time and the question asked with each, "What is missing in this picture?" Three correct replies required.

34. "What day is today?" "What date is it?"

35. "I am going to say five numbers. Listen well and repeat them exactly: $3,8,5,7,1 ; 9,2,7,3,6$; and $5,1,8,3,9$." One group given at a time. One exact response required.

\section{Mental Age 9 Years.}

36. In a pile before the child place the following coins:Ten pemnies, two nickles, two dimes, one quarter, one half-dollar. Then propose a game of store keeping, the child to keep the store and use the pile of money to make change, the experimenter to be the customer. Add some articles for sale. Then buy something for four cents. Give the child a quarter and require the change.

37. Test No. 22. Credit given for No. 37 if three definitions superior to use are given.

38. Show the child successively a penny, a dime, a dollar, a quarter, a nickle, a half-dollar, a two dollar bill, a ten dollar bill, a five dollar bill. Ask, "What is this?" with each.

39. Name the months of the year in order. One crror allowed; time 15 seconds.

40. (a) "If you were going away and missed your train, what would you do?"

(b) "If one of the boys should hit you without meaning to, what would you do about it?"

(c) "If you broke something belonging to someone else, what would you do about it?" Two good responses required.

\section{Mental Age 10 Years.}

41. Place on the table before the child five boxes weighing $3,6,9,12$ and 15 grams respectively. Say to him, "These little boxes all weigh different amounts. Some are heavier and some 
lighter. I want you to place the heaviest here and by its side the one which is a little less heavy, and next to it one still a little less heavy, and then one a little less heavy than that, and finally here the lightest." Three trials made, the boxes mixed after each. Two successes in three are required.

42. "I am going to show you two drawings, and after you have looked at them I shall take them away and ask you to draw them from memory. You must look at them closely because you will only have them for ten seconds, and this is a very short time." (Drawings shown in Figure 8.)

Full credit is given if the whole of one drawing and half of the other is reproduced exactly.

43. "I am going to read you some sentences; in each one of them there is something foolish or absurd. You listen carefully and tell me each time what it is that is foolish."

(a) "An unlucky bicycle rider fell on his head and was instantly killed; they took him to the hospital and fear that he cannot get well." After a pause- "What is foolish in that?"

(b) "I have three brothers-Paul, Ernest, and myself.""What is foolish in that?"

(c) "The body of a young girl cut into 18 pieces was found yesterday. People think that she killed herself."-"What is foolish in that?"

(d) "There was a railroad accident yesterday, but not a serious one; only 48 persons were killed."- "What is foolish in that?"

(e) "A man said: 'If I should ever grow desperate and kill myself, I should not use Friday, because Friday is an unlucky day and might bring me unhappiness," - "What is foolish in that?"

Correct solution of three of the five statements required.

44. (a) "If you were delayed on your way to school, what would you do about it?" 
(b) "Before taking part in something very important, what would you do?"

(c) "Why do we more easily pardon a bad act done in anger than a bad act done without anger?"

(d) "If someone should ask your opinion of one whom you did not know very well, what would you say?"

(e) "Why should we judge a person by his acts rather tnan by his words?"

Two errors allowed.

45. Write the words Paris, fortune, stream. Show them to the child, reading them to him several times. Then give him pen and ink and tell him to write a sentence containing all three of these words.

Full credit is given for two sentences containing the three words.

\section{Mental Age 12 Years.}

46. "Which is the longer of these two lines?" (Figure 13.) "Which is the longer of these two lines?" (Figure 14.)

"Which is the longer of these two lines?" (Figure 15.)

"And of these?" (Figure 16.)

"And of these?" (Figure 17.)

"And of these?" (Figure 18.)

Full credit given if suggestion of longer line to the right does not hold in two of last three pair.

47. Test 45. Credit given for one sentence containing the three words.

48. "I want you to say just as many words as you can in three minutes. Some boys say as many as two hundred. Now you must try and see how many you can think of."

Sixty words the minimum accepted.

49. "What does charity mean?" "What does justice 
mean?" "What does kindness mean?" Two correct answers required.

50. "Find the sentences which these words make. Fix the words in their proper order." (Fig. 9.)

(a) For-an-the-at-hour-early-we-country-started.

(b) To-asked-spelling-my-I-teacher-correct-my.

(c) A-defends-dog-good-his-master-bravely.

NORMAL

\section{Mental Age 15 Years.}

51. "I am going to say seven numbers. Listen well and repeat them exactly: $4,9,2,6,1,3,7 ; 9,3,5,1,8,2,6$; $2,7,4,9,3,8,5$." One success in three required.

52. "Do you know what the word 'rhyme' means? Two words which rhyme are two words which end in the same sound. Thus, pumpkin rhymes with napkin. Pump-kin, nap-kin. They both end in kin. The same way mutton rhymes with button: Mut-ton and but-ton. They both end in ton. Do you understand? Now I am going to give you a word, and you try to find all the words which rhyme with it. The word is money. Find all the words which rhyme with 'money." "*

Three words required in one minute.

53. "Listen carefully and repeat exactly what I say: The other day I saw on the street a pretty yellow dog. Little Morris has soiled his nice new apron."

54. Tests Nos. 9 and 27. Ask the same questions. Full credit given if two pictures are intepreted.

*Money is substituted here for the French word, obéissance, the English form for which, obedience, is not adapted to rhyming, while the word obey, our first substitution, leads to such rhymes as, stay, hay, day, etc., which are not satisfactory. 
55. (a) "A woman was walking through a park in Chicago. Suddenly she stopped, dreadfully frightened. She ran to the nearest policeman and told him she had seen hanging to the limb of a tree"-After a pause-"A what?"

(b) "My neighbor has just received some singular visits; one after another, a doctor, a lawyer, and a priest called. What is happening at my neighbor's?"

Full credit given only if both problems are answered satisfactorily.

\section{ADULT.}

56. "Here is a paper. folded in four; suppose that here (pointing to a small triangle which has been drawn in the middle of that edge which consists of but a single fold) I cut out this little triangle of paper. Now if I unfold the paper, how would it look? Draw the paper as it would appear if unfolded. and show how and where it would be cut." (Fig. 10.)

Requirements: Two diamonds drawn in line with each other and each in the center of one-half of a square.

57. An oblong card cut in two along a diagonal is placed in position before the subject. "Look well at the lower piece of card. Suppose that I lift it and place this edge (tracing the edge $a-c$ with the finger) on this edge ( $a-b$ of the upper piece). Suppose further that this point $(c)$ is placed just on this point (b). Now I take away the piece; in your imagination, place it as I həve described and draw its outline in this position. Commence by following the outline of the upper piece." (Fig. 11.)

It is required that a right angle be represented at (b) and that the edge a-c be shorter than the edge a-b.

58. "What is the difference between laziness and idleness?" "What is the difference between event and advent?" "What is the difference between evolution and revolution?" Treo correct responses required.

59. "There are three principal differences between a King and a President of a Republic. What are they?" 
Required answer: Royalty is hereditary, the tenure of office is for life, and its powers are very great; the president is elected, his tenure of office is limited, and his powers are less extensive.

60. "Listen attentively to what I am about to read. After finishing, I shall ask you to repeat the sense of the selection: Many opinions have been given on the value of life. Some call it good, others call it bad. It would be more just to say that it is mediocre, for on the one hand our happiness is never so great as we would have it, and on the other hand our misfortunes are never so great as others would have them. It is this mediocrity of life which makes it just, or rather, which prevents it from being radically unjust.

It is required that the thought of this selection be understood. 


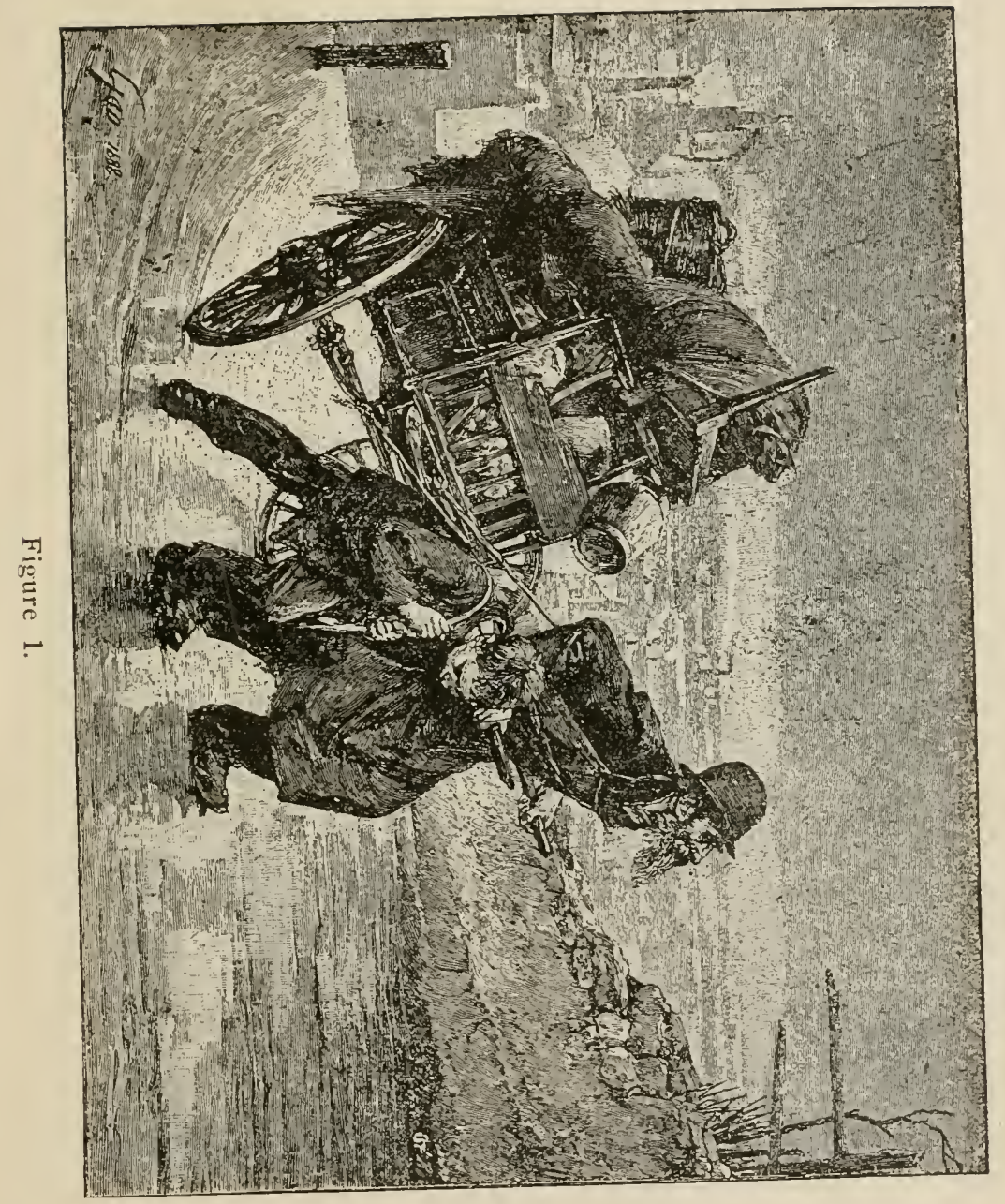




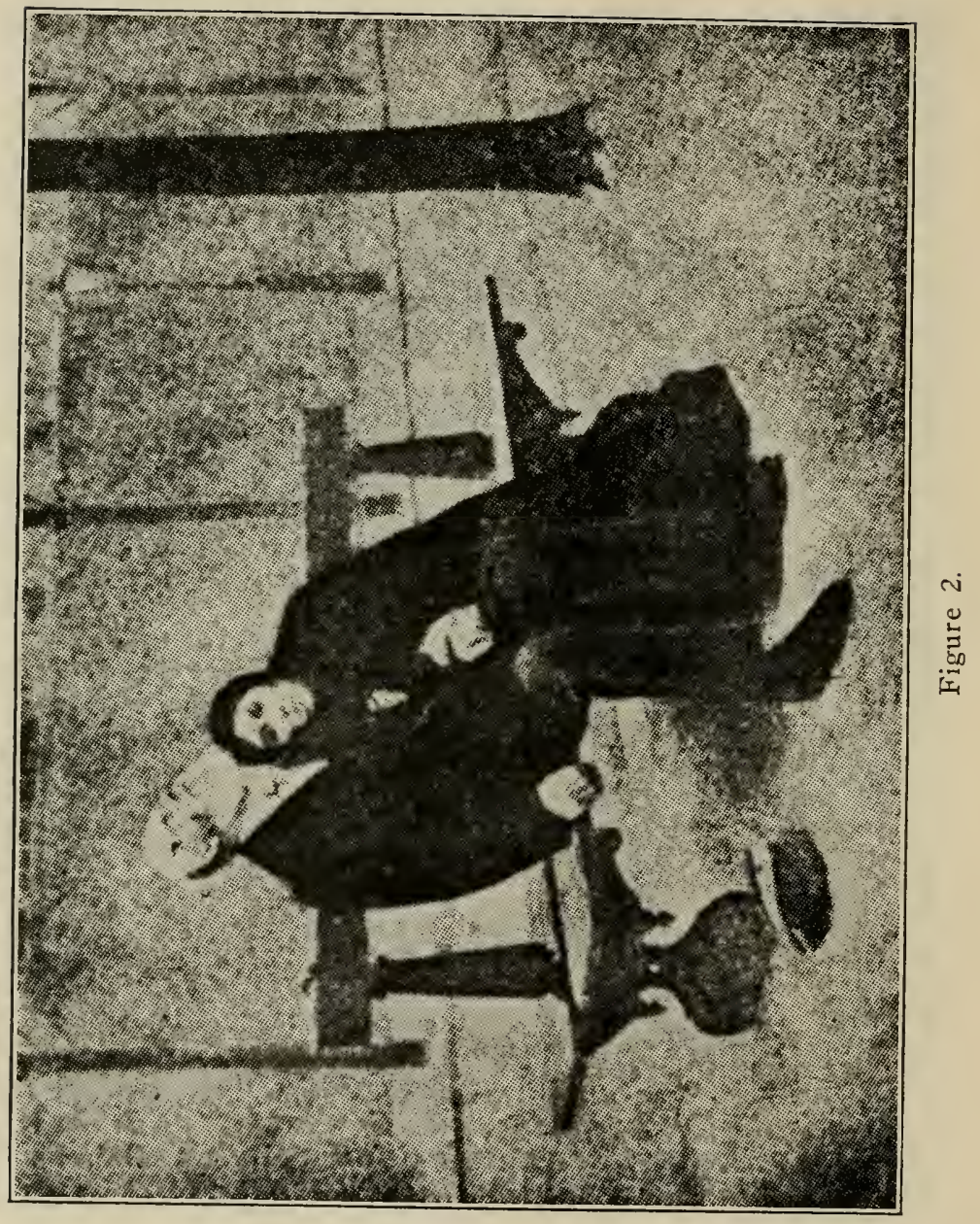




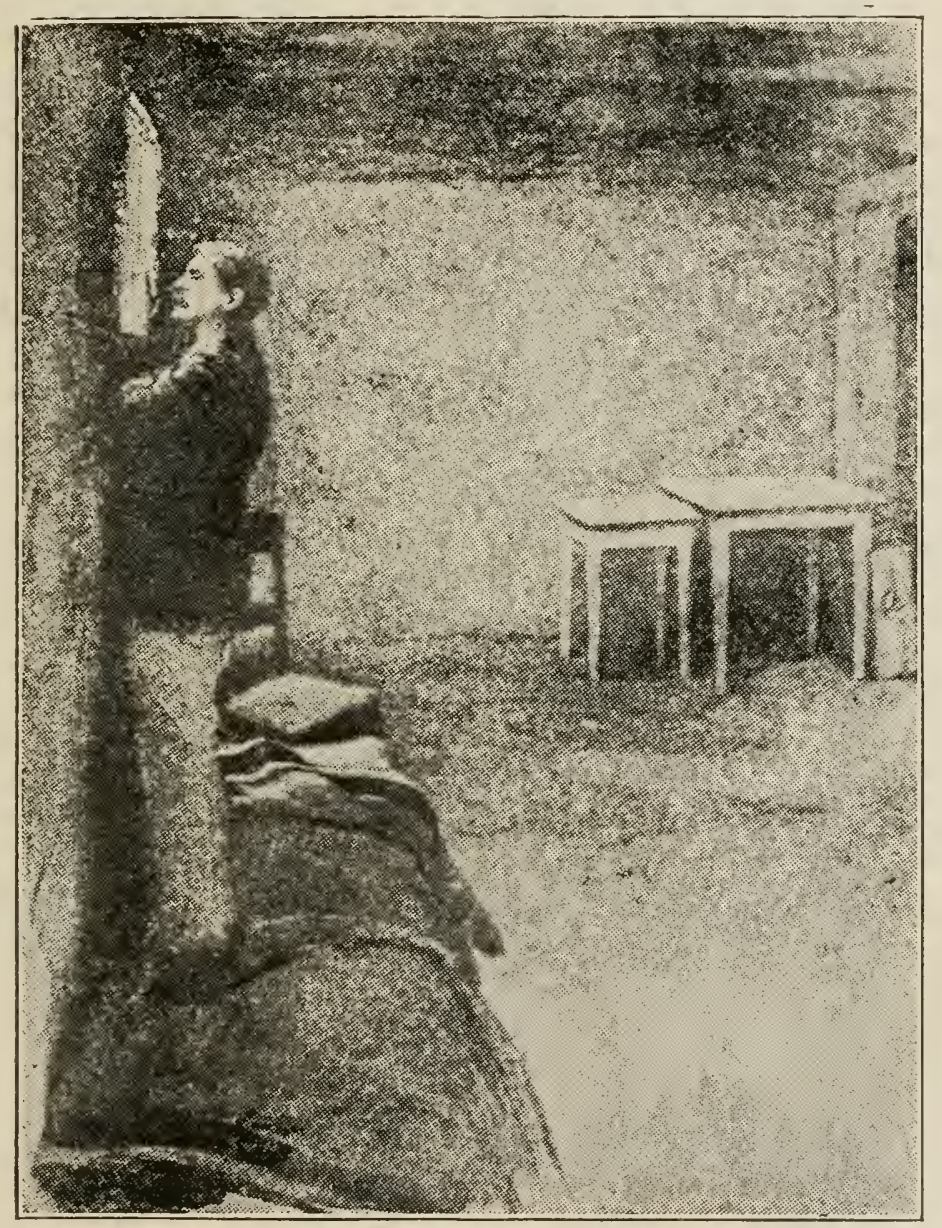

Figure 3. 

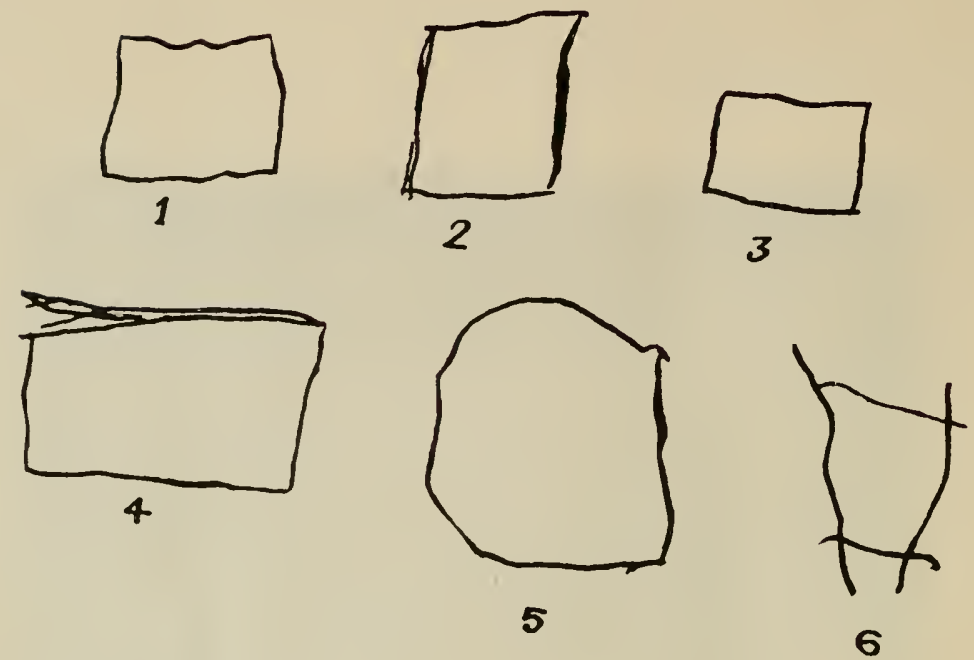

Figure 4.
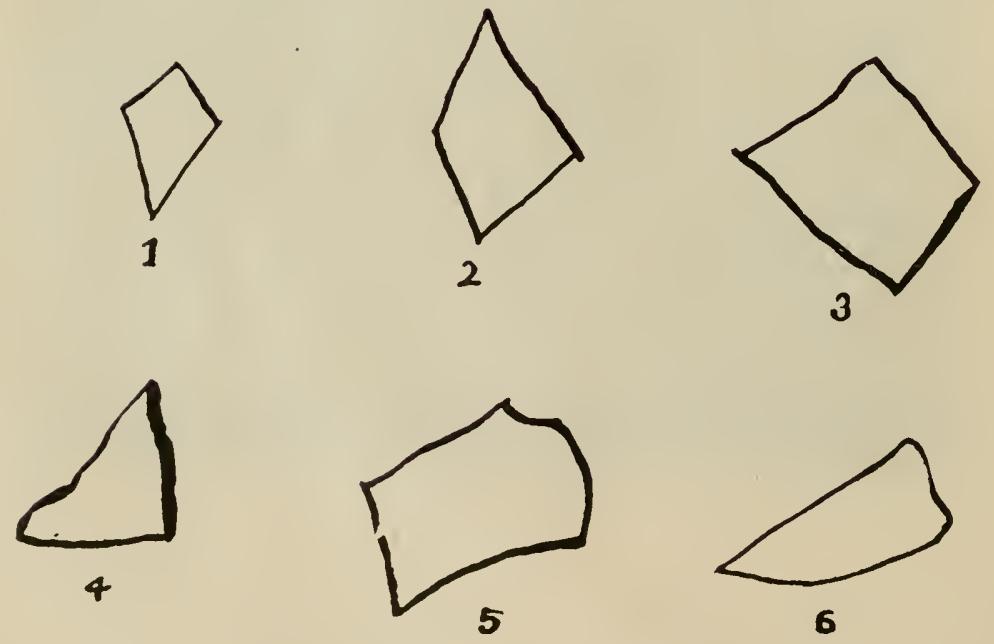

Figure 5. 

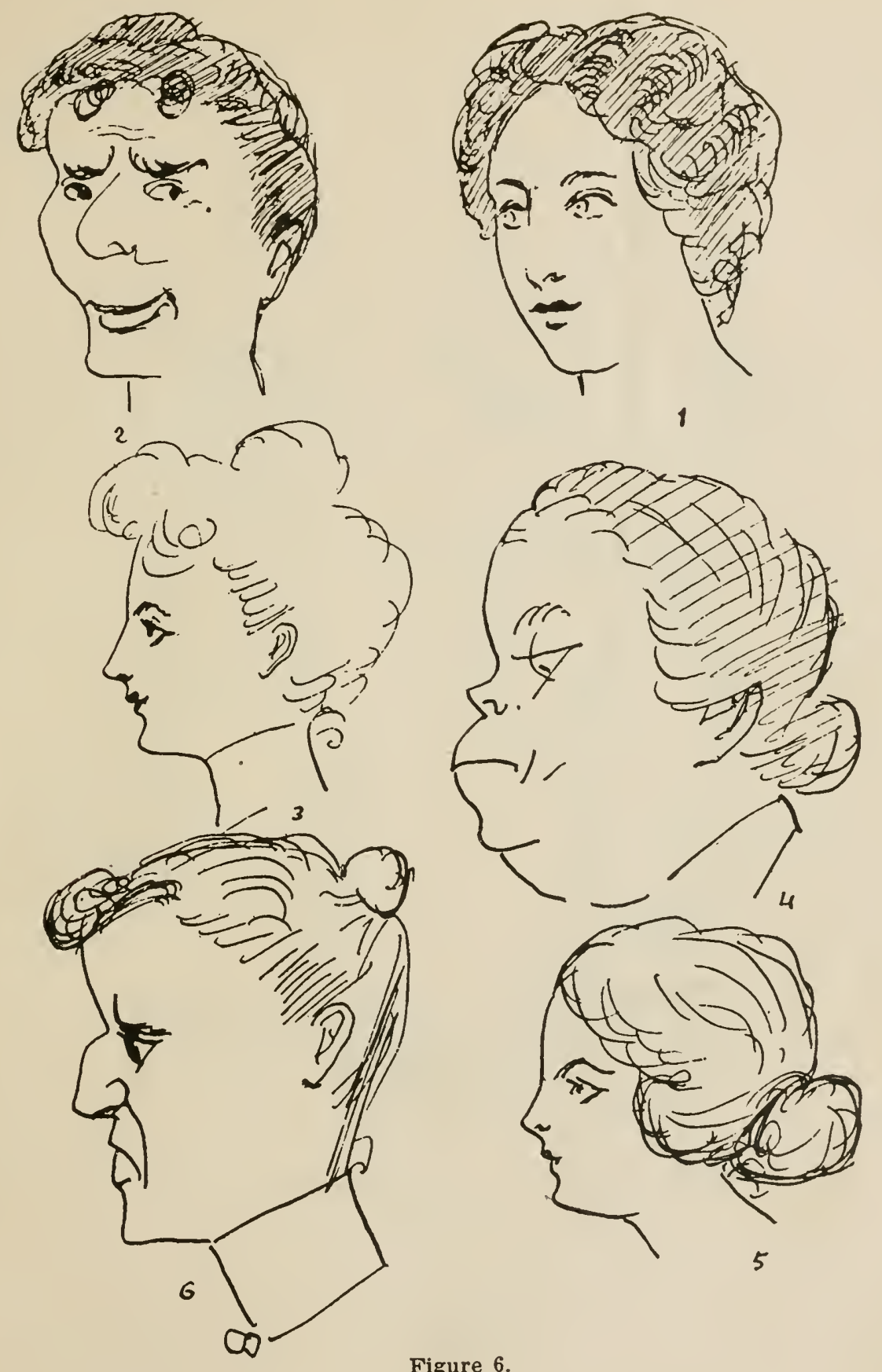

Figure 6. 

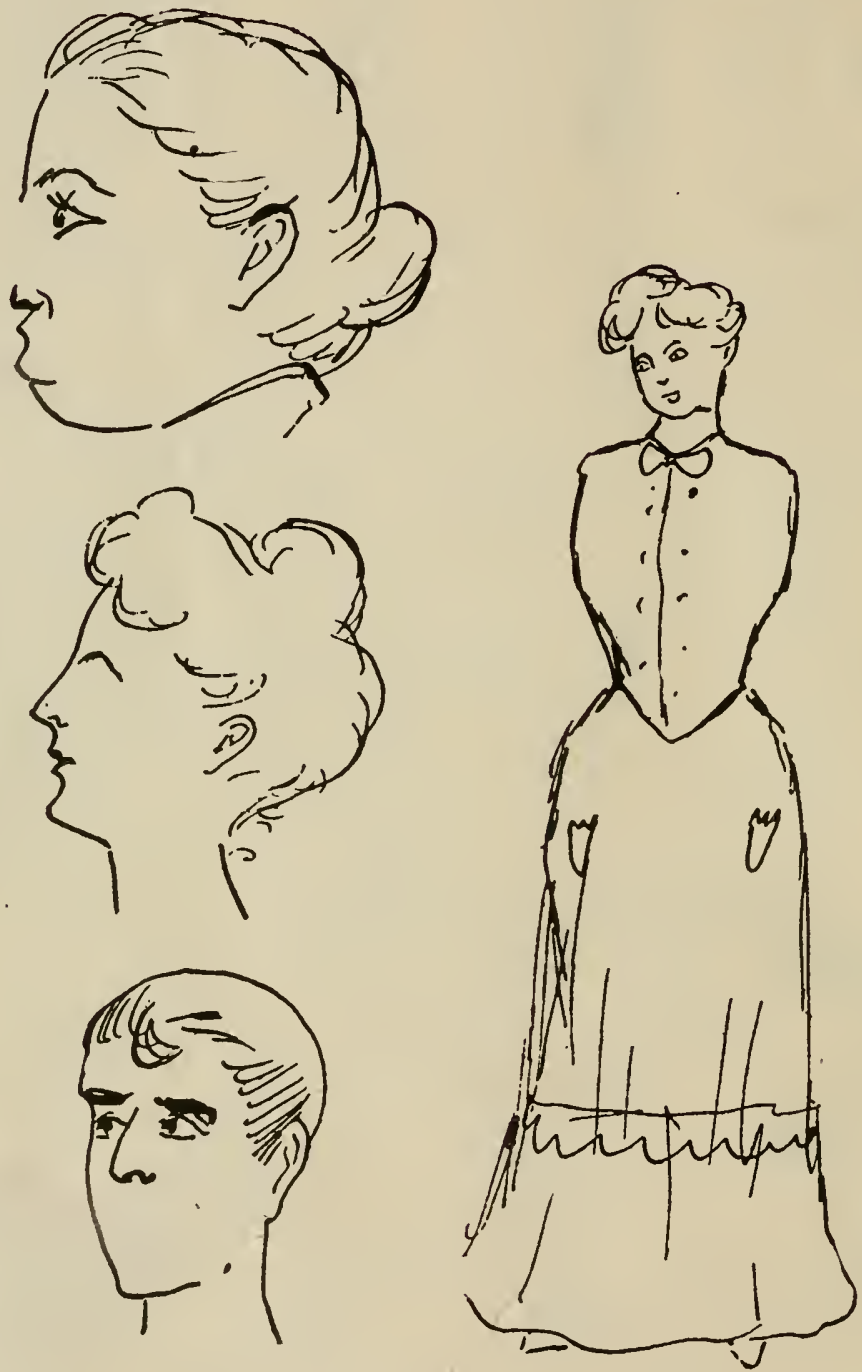

Figure 7. 

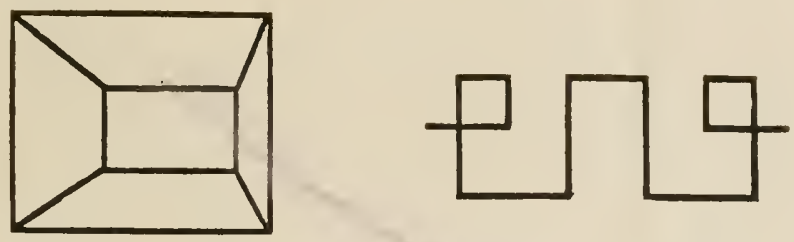

Figure 8.

For An The

At Hour Early

We Country Started

To Asked Spelling My I Teacher

Correct $\mathrm{My}$

\section{A Defends \\ Dog Good His \\ Master Bravely}

Figure 9. 


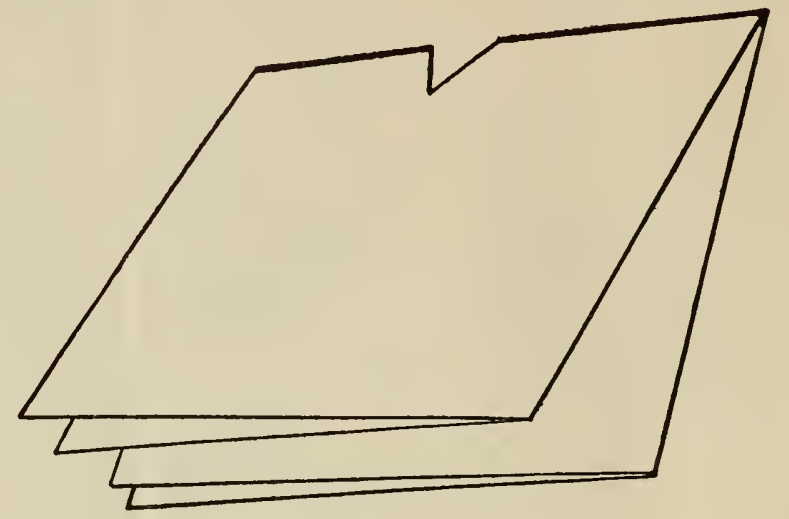

Figure 10.

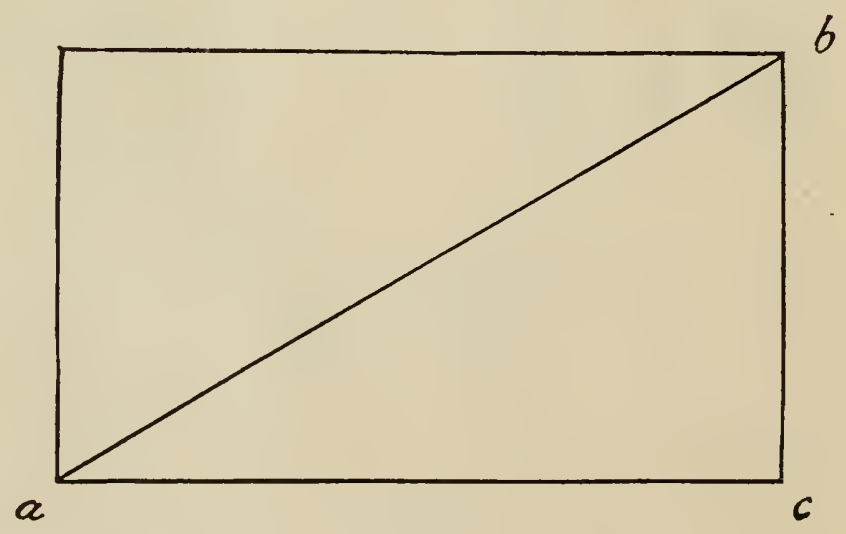

Figure 11. 


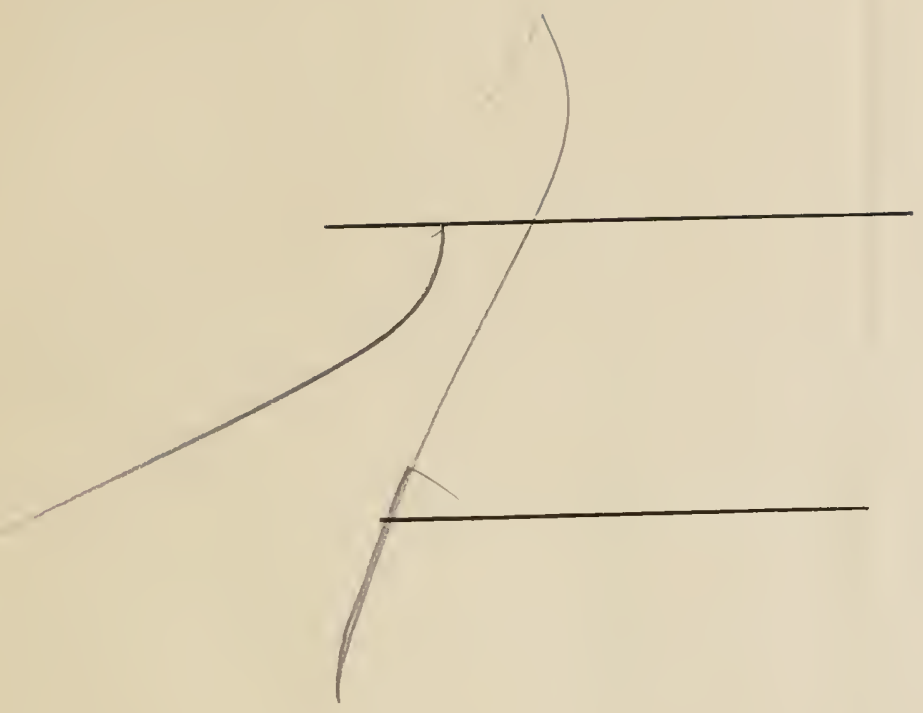

Figure 12. 
<smiles>C=C</smiles> 


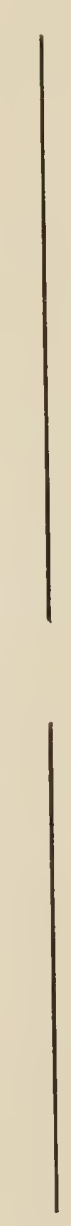




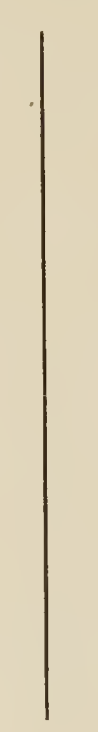





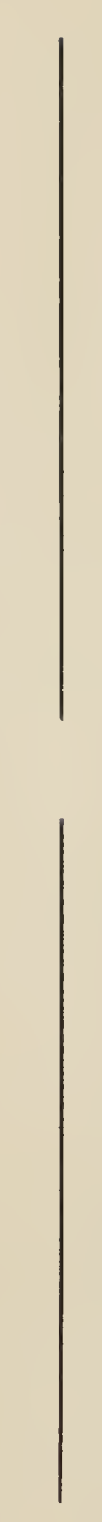




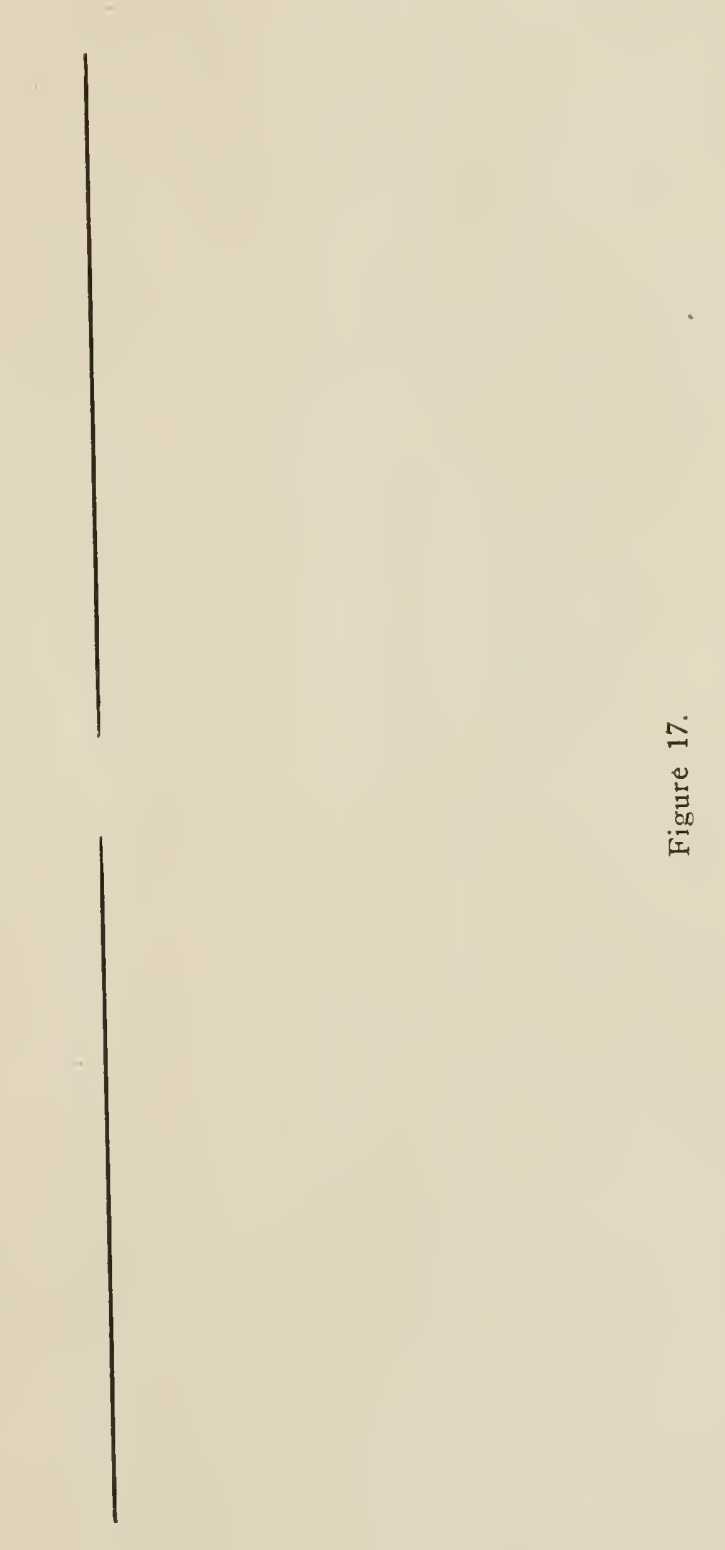




$$
\begin{array}{|}
\mid \\
\mid
\end{array} \mid
$$


-

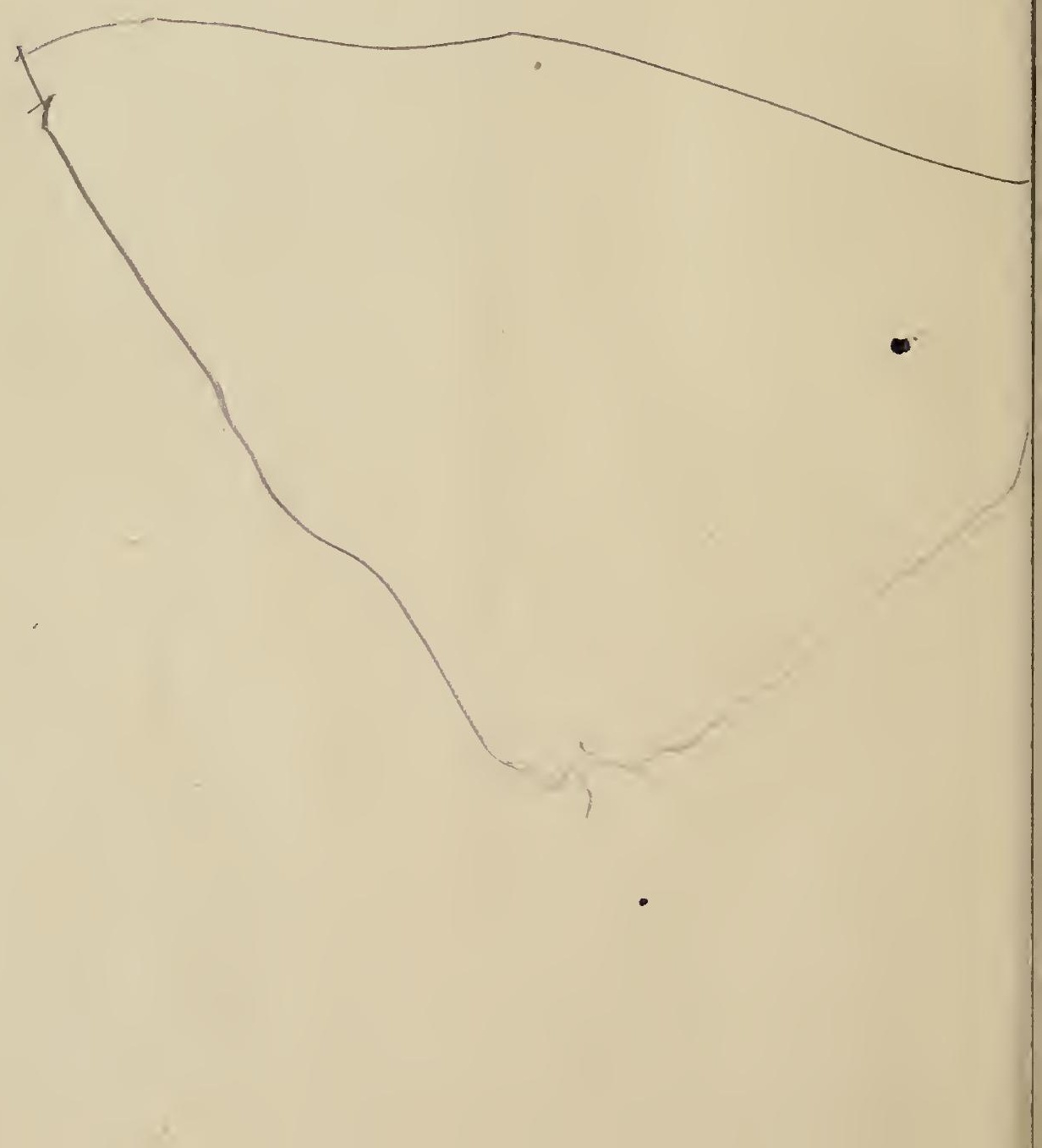




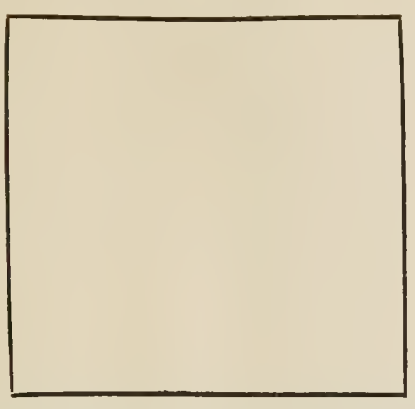

Figure 19.

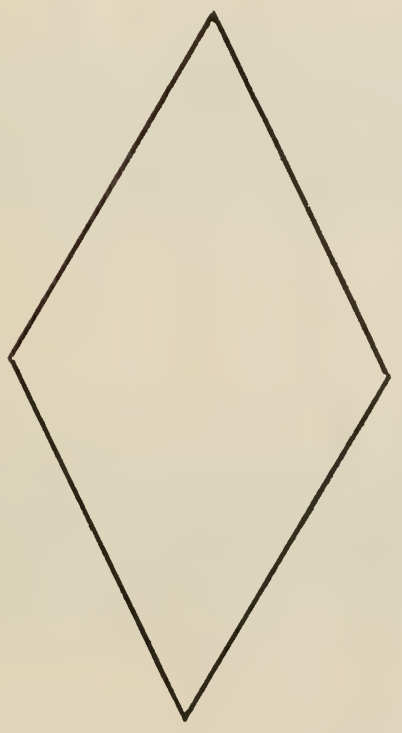

Figure 20. 


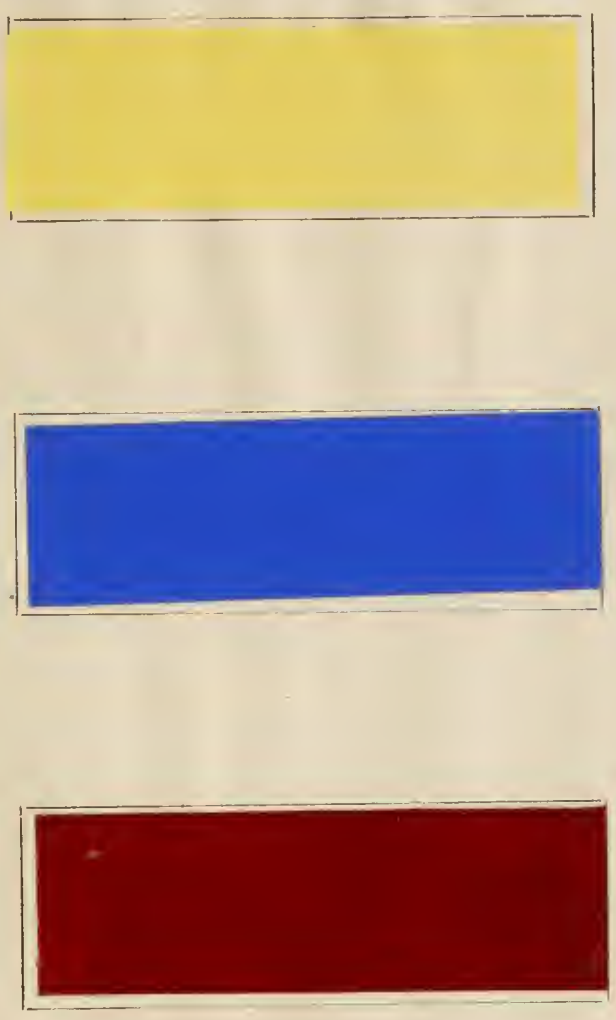

Figure 21 
, 


\section{RETURN CIRCULATION DEPARTMENT}

TO $\rightarrow 202$ Main Library

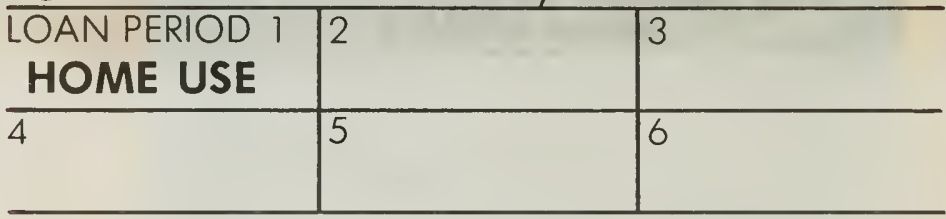

ALL BOOKS MAY BE RECALLED AFTER 7 DAYS

Renewals and Recharges may be made 4 days prior to the due date.

Baoks may be Renewed by calling $\quad 642-3405$

\section{DUE AS STAMPED BELOW}

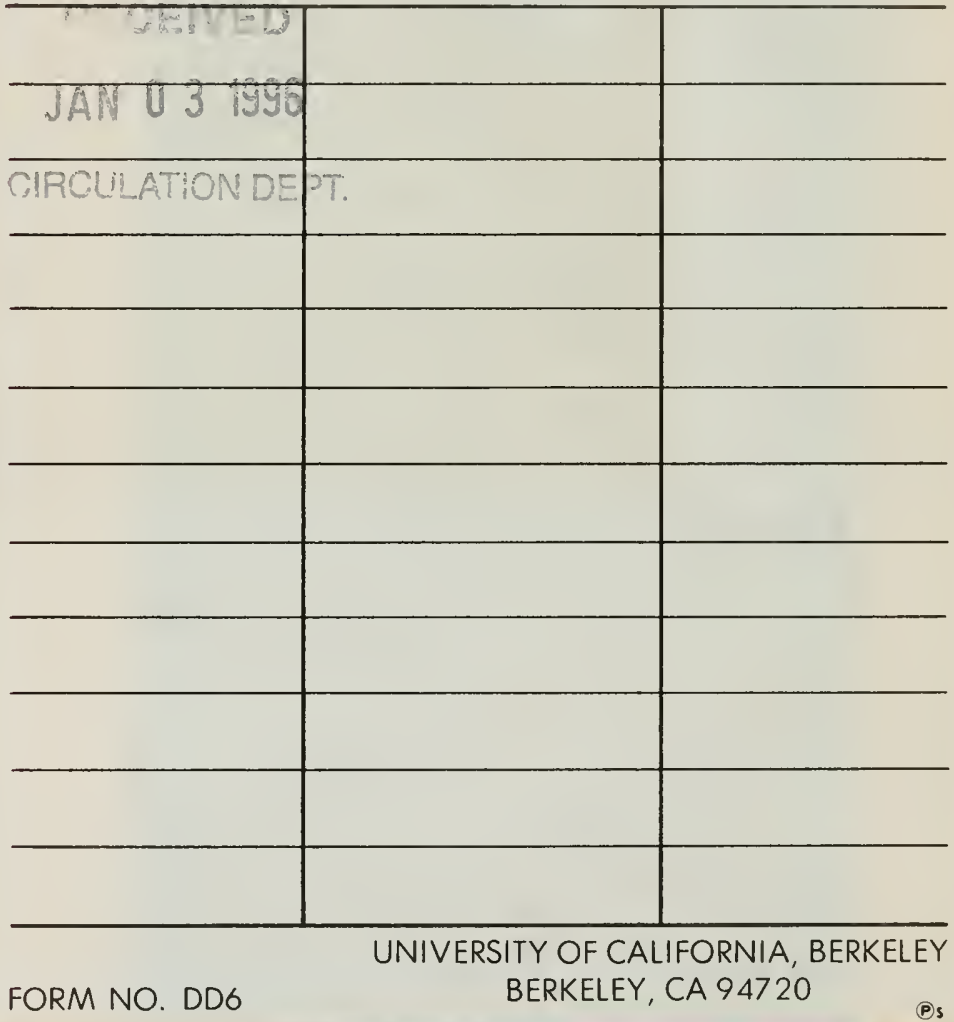




\section{YD 22584}

U. C. BERKELEY LIBRARIES

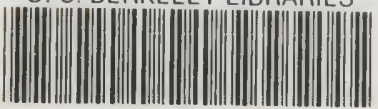

C056067?72
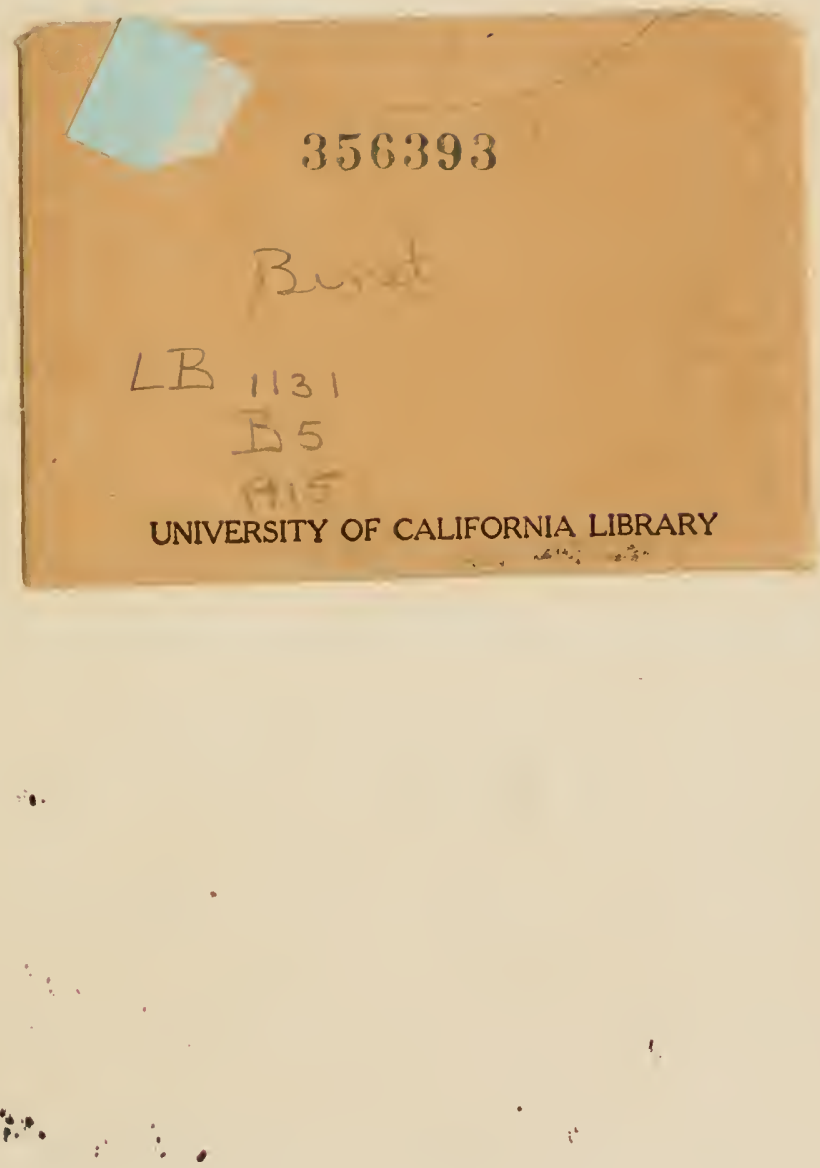
